\title{
A Novel Exercise Thermophysiology Comfort Prediction Model with Fuzzy Logic
}

\author{
Nan Jia, ${ }^{1}$ Liang Yu, ${ }^{1}$ KaiXing Yang, ${ }^{1}$ RuoMei Wang, ${ }^{1}$ XiaoNan Luo, ${ }^{1,2}$ and QingZhen Xu${ }^{3}$ \\ ${ }^{1}$ School of Data and Computer Science, Sun Yat-Sen University, Guangzhou, China \\ ${ }^{2}$ School of Computer and Information Security, Guilin University of Electronic Technology, Guilin, China \\ ${ }^{3}$ School of Computer, South China Normal University, Guangzhou, China \\ Correspondence should be addressed to XiaoNan Luo; lnslxn@mail.sysu.edu.cn
}

Received 20 September 2016; Accepted 8 November 2016

Academic Editor: Qingchen Zhang

Copyright (C) 2016 Nan Jia et al. This is an open access article distributed under the Creative Commons Attribution License, which permits unrestricted use, distribution, and reproduction in any medium, provided the original work is properly cited.

\begin{abstract}
Participation in a regular exercise program can improve health status and contribute to an increase in life expectancy. However, exercise accidents like dehydration, exertional heatstroke, syncope, and even sudden death exist. If these accidents can be analyzed or predicted before they happen, it will be beneficial to alleviate or avoid uncomfortable or unacceptable human disease. Therefore, an exercise thermophysiology comfort prediction model is needed. In this paper, coupling the thermal interactions among human body, clothing, and environment (HCE) as well as the human body physiological properties, a human thermophysiology regulatory model is designed to enhance the human thermophysiology simulation in the HCE system. Some important thermal and physiological performances can be simulated. According to the simulation results, a human exercise thermophysiology comfort prediction method based on fuzzy inference system is proposed. The experiment results show that there is the same prediction trend between the experiment result and simulation result about thermophysiology comfort. At last, a mobile application platform for human exercise comfort prediction is designed and implemented.
\end{abstract}

\section{Introduction}

In the modern society, people are more and more health conscious to improve their life quality. Exercise is often the first step in lifestyle modifications for health maintenance and management $[1,2]$. Participation in a regular exercise program can help improve various aspects of cardiovascular function, with reduction in the risk for osteoporosis. Importantly, reductions in risk factors associated with disease states (heart disease, diabetes, etc.) can improve health status and contribute to an increase in life expectancy [3].

During exercise, the human body exchanges energy with the clothing system and environmental conditions in different forms of heat transfer; when the whole human-clothingenvironment (HCE) system comes to a thermal steady state, physiological thermal neutrality is reached and the human body will be in a proper thermal and hydration state $[4,5]$. A healthy exercise should be thermophysiology comfort for people during exercise. Some parameters can be used to evaluate the thermophysiology comfort, which are temperature, moisture, and physiological properties of heart rate, blood pressure, and so on.

Research on thermophysiology comfort is important for healthy exercise. Based on the thermophysiology comfort model, the human thermal and physiological status can be described and used to predict some accidents like dehydration, exertional heatstroke, syncope, and even sudden death. If these accidents can be analyzed or predicted before they happen during exercise, it will be beneficial to alleviate or avoid disease or mortality. At the Standard Chartered Hong Kong Marathon 2013, 55 runners were reported to have fallen unconscious, to have been rendered comatose, and to have suffered from collapse because of heatstroke [6].

Some landmark research results can be reviewed [7, 8]. Researches about simulating human dynamic thermal comfort in the human-clothing-environment system were presented [9-11]. Wang et al. [9] applied an adaptive neural fuzzy network in the clothing comfort evaluation model. Kingma et al. [10] developed a mathematical model for thermal sensation based on the neurophysiology of thermal 
reception. Huizenga et al. [11] reported a model of human physiology and comfort for assessing complex thermal environments. However, limitations have also been identified. There is a lack of enough considerations on the effects of human physiological performances in the thermophysiology comfort prediction. The human body physiological simulation model needs to be enhanced on the dynamic heat and moisture transfer in the human-clothing-environment system.

In this paper, a novel thermophysiology simulation and exercise comfort prediction model is reported. Based on the HCE system, a nonlinear heart rate regulation model and the 25 -node thermal regulation model are integrated together to simulate the human physiological performance like temperature, sweat rate, and heart rate. The thermal performance and physiological status of the human body can be simulated in this improved model. Comparisons among different cases show that the improved model can describe the human thermophysiology behavior in the exercise very well. And there is the same prediction trend on the experiment result and simulation result about the thermophysiology comfort.

The main contributions are as follows:

(i) Integrate nonlinear heart rate regulation model into the human thermal physiological simulation model; some important thermophysiology parameters during exercise can be simulated by this integrated model.

(ii) Present a novel exercise thermophysiology comfort prediction model according to the integrated model, which can be used to describe the thermophysiology phenomenon during exercise.

(iii) Implement a mobile application for comfort prediction, in which people get their physiological comfort status according to the exercise information.

The rest of this paper is organized as follows. Related work is introduced in Section 2. An integrated thermal and physiological simulation model in the human-clothing-environment system is reported in Section 3. A novel thermophysiology comfort prediction model with fuzzy logic is presented in Section 4. In Section 5, case studies are designed in different scenes to validate the proposed models. And, in Section 6, a mobile application for comfort prediction is designed and implemented. Finally, conclusion is drawn.

\section{Related Work}

Research on exercise thermophysiology comfort prediction model involves multidisciplinary knowledge; the human body, clothing, and the environment are a coupled system in the heat and moisture transfer process. The phenomenon of heat and moisture transfer in the HCE system has a significant effect on the human thermophysiology comfort sensation. Figure 1 shows the main components of heat and moisture transfer in HCE system.

From Figure 1, it can be found that the human-clothingenvironment system consists of three sets of mathematical models: (1) mathematical description of the thermoregulation of the human body; (2) mathematical description of the heat and moisture transfer processes in clothing; and (3) mathematical description of the coupled heat and moisture transfer processes in the external environment. Based on the simulation results, some thermal and physiological performances can be obtained and used to predict the thermophysiology comfort.

Some research results on heat and moisture transfer in HCE system can be reviewed [12,13]. Henry proposed mathematical models to simulate the coupled heat and moisture transfer processes in textile fibers [14]. Farnworth developed a numerical solution of the models with the linear assumption [15]. Li et al. further improved the models by incorporating fiber moisture absorption/desorption mechanisms derived from experimental data into the computations [16, 17]. Further development of the mathematical models has taken into account more physical mechanisms such as the liquid water diffusion [18], radiation effects [19], phase change materials [20], pressure gradients [21], and the effect of gravity [22]. The thermal behavior in clothing is simulated.

Mathematical models describing the thermoregulatory system of the human body have been the subject of research for years. Reviewed by Cheng and Fu [23, 24], all the models for the entire body can be characterized in terms of their viewpoint of development. They are (1) one-node models [25], (2) two-node models [26], (3) multinode models [2729], and (4) multielement models [30,31]. Though most of them are likely to produce acceptable results under conditions of heat stress when temperature is relatively uniform throughout the body, multinode and multielement models seem to deal better with exposure to cold when large temperature gradients are developed within the body. In the human thermal regulation system, a series of physiological regulatory behaviors (sweating, vasodilatation, shivering, and vasoconstriction) whenever in hot or cold external thermal environments are simulated.

Considering the interactions in the HCE system, the development of a mathematical model of the coupled heat and moisture transfer processes in the external environment is accomplished by the boundary condition equations that refer to the thermal status of the external environment and body [32]. Based on the HCE system, for the given values of humidity, air speed, metabolic rate, and clothing insulation, some simulation results on temperature, moisture, and physiological properties of heart rate and blood pressure can be obtained.

Computer evaluation model is widely used to predict human comfort. Li described the thermophysiological comfort as attainment of a comfortable thermal and wetness state [33]. Wong et al. reported research on neural network predictions of human psychological perceptions of clothing sensory comfort [34] and predicted clothing sensory comfort with artificial intelligence hybrid models [35]. Wang et al. presented the mathematical simulation of the perception of fabric thermal and moisture sensations [36]. Luo et al. presented a fuzzy neural network model for predicting clothing thermal comfort [37]. And Wang et al. designed an adaptive 

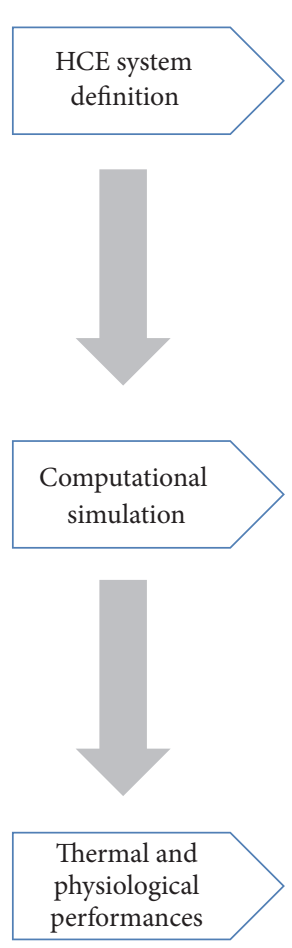
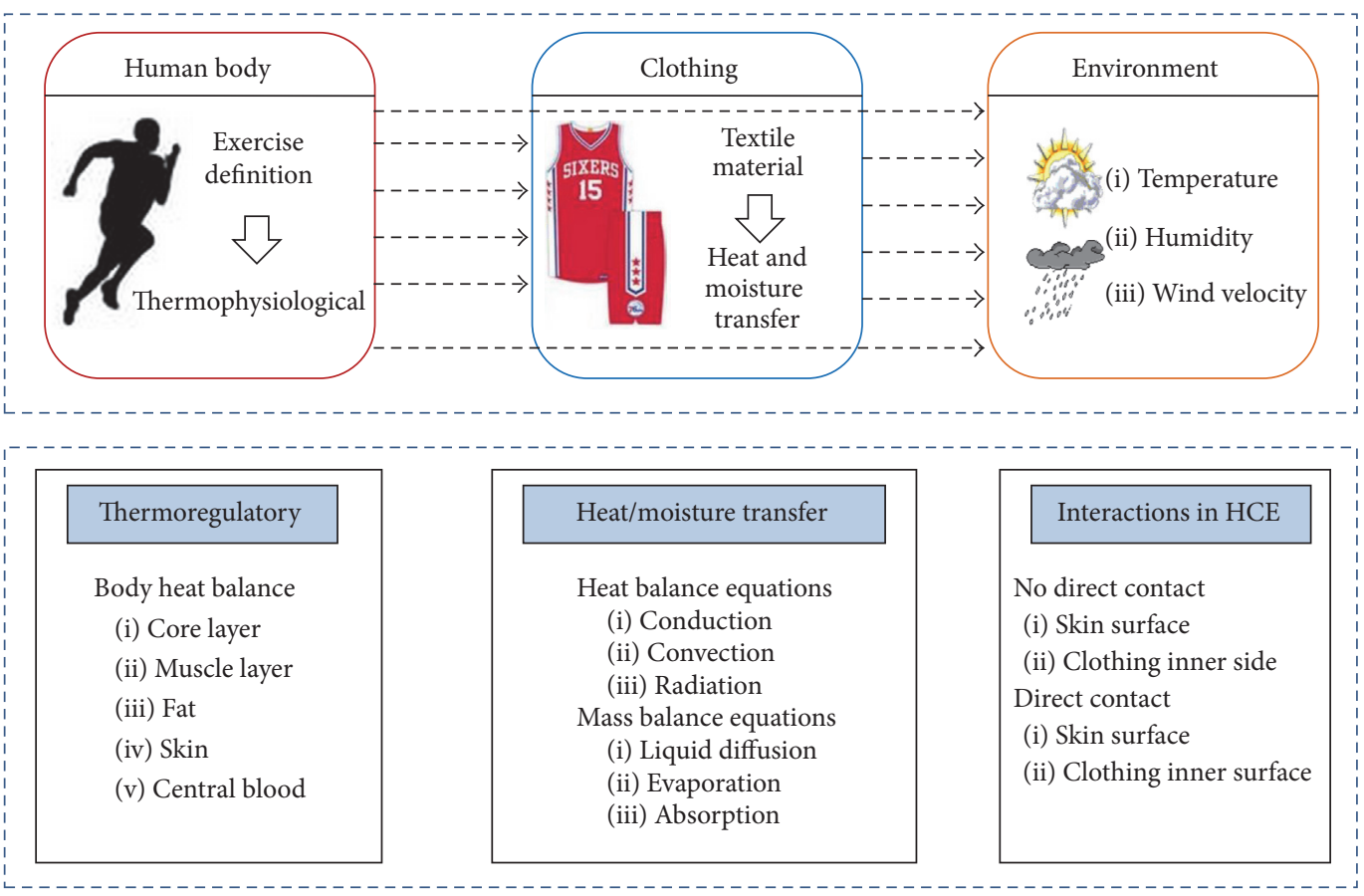
is Temperature of skin
¿ Relative humidity of skin
is Core temperature
is Evaporative heat
is Sweat rate blood flow
$\sum$ Volume of skin
is Heart rate
is Blood pressure
is Thermophysiological

FIGURE 1: Main components of heat and moisture transfer in HCE system.

neural fuzzy network to build a clothing comfort evaluation model [9].

Although much progress has been made, there are knowledge gaps that need to be filled in individual areas. They are as follows:

(i) There are insufficient advances on the modeling of human body physiological mechanisms during the thermoregulatory processes. Some physiological parameters cannot be simulated in the heat and moisture transfer.

(ii) There is a lack of advances in mathematical modeling of thermophysiology comfort, especially in dynamic heat balance and thermoregulation of a clothed human body.

This paper, therefore, aims to improve the HCE system simulation model and obtain more human body's physiological indicators during exercise, to design a novel exercise thermophysiology comfort prediction model. Figure 2 illustrates the schematic diagram of the thermophysiology comfort prediction model in HCE system reported in this paper.

As shown in Figure 2, the heat and moisture transfer in human-clothing-environment system evokes the effecter mechanisms of the thermoregulatory system to regulate the thermal status of the human body. Based on the 25node human thermoregulatory model, a nonlinear heart rate regulation model is added to improve human thermal and physiological mode. The improved human thermal and physiological model can be used to describe the human physiological behavior as well as the heart rate regulation behavior during exercise. Many physiological indicators (like core temperature, heart rate, etc.) can be simulated also. According to these simulation results, the fuzzy process of thermophysiology comfort model is used to predict the thermal comfort and health status. The detailed description is shown in the following sections.

\section{An Improved Thermal and Physiological Simulation Model in the HCE System}

According to the schematic diagram of thermophysiology comfort prediction model shown in Figure 2, it is important to model a reasonable mathematical model to represent the thermal and physiological behaviors in the HCE systems. Considering the feasibility and efficiency of the whole simulation process, we adapt an improved thermal physiological model which comprises a 25 -node thermal regulatory model and a nonlinear heart rate regulation model for describing the thermal and physiological regulation system of the human 


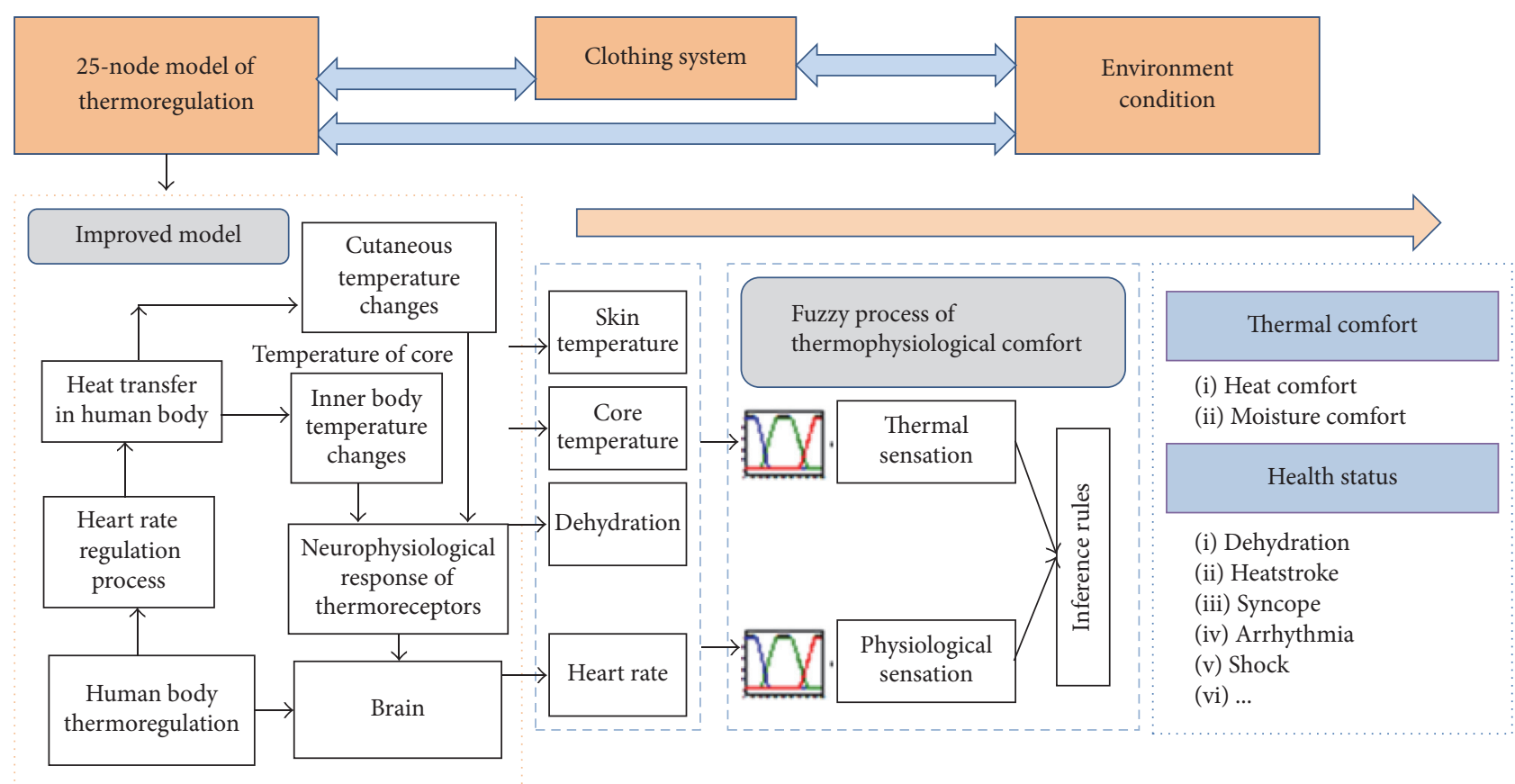

FIGURE 2: Schematic diagram of thermophysiology comfort prediction model.

body, as well as a coupled heat and moisture transfer model for clothing.

3.1. Improved Thermal Physiological Model of the Human Body. During exercise, the human body activates effective thermoregulatory mechanisms to make the body in a proper thermal status. When the temperature of the human body increases, several physiological reactions are activated automatically to speed up body heat dissipation such as sweating and automatically adjusting the cardiovascular system. During cardiovascular adjustment, the blood is redistributed from the core organs to the skin to facilitate heat dissipation, and the active muscles require blood supply to deliver oxygen for maintenance of activity. Meanwhile, the heart rate (HR) increases to sustain cardiac output and blood supply to the working muscles and the skin [38].

Human thermoregulatory model can be referenced from previous researches $[28,39]$. Compared with other models, in this paper, we select 25-node model as the human thermoregulatory model. The more advantages of this model are more accurate physiological simulation performances and efficient numerical computation time cost. In the 25-node model, the human body is divided into six parts: head, trunk, arms, hands, legs, and feet. Each part is expressed by four concentric layers individually representing the core, muscle, fat, and skin layers of the human body, in which all layers are connected by a central blood pool representing large arteries and veins in the body [39]. The thermoregulatory mechanisms of the human body are represented by the mathematical equations core layer:

$$
\begin{aligned}
C(i, 1) \frac{d T(i, 1)}{d t}= & Q(i, 1)-B(i, 1)-D(i, 1) \\
& -\operatorname{RES}(i, 1)
\end{aligned}
$$

muscle layer:

$$
\begin{aligned}
C(i, 2) \frac{d T(i, 2)}{d t}= & Q(i, 2)-B(i, 2)+D(i, 1) \\
& -D(i, 2)
\end{aligned}
$$

fat layer:

$$
\begin{aligned}
C(i, 3) \frac{d T(i, 3)}{d t}= & Q(i, 3)-B(i, 3)+D(i, 2) \\
& -D(i, 3)
\end{aligned}
$$

skin layer:

$$
\begin{aligned}
C(i, 4) \frac{d T(i, 4)}{d t}= & Q(i, 4)-B(i, 4)+D(i, 3)-E(i, 4) \\
& -Q_{t}(i, 4)
\end{aligned}
$$

central blood:

$$
C(25) \frac{d T(25)}{d t}=\sum_{i=1}^{6} \sum_{j=1}^{4} B(i, j),
$$


where $i$ is the part number of the human body, $j$ is the layer number in each part, $C(i, j)$ is the thermal capacity of each node $(i, j), C(25)$ is the thermal capacity of central blood, $T(i, j)$ is the temperature of each node, $T(25)$ is the temperature of central blood, $Q(i, j)$ is the metabolic heat generation, $Q_{t}(i, 4)$ is the dry heat loss on the skin surface, $B(i, j)$ is the thermal exchange between each node and central blood, $D(i, j)$ is the thermal conduction between adjacent layers, $E(i, j)$ is the heat loss by evaporation, and $\operatorname{RES}(i, 1)$ is the heat loss by respiration.

For the control system of model, we have skin blood:

$\mathrm{BF}(i, 4)=\frac{\operatorname{BFB}(i, 4)+\left(\operatorname{SKINV}(i) \times D_{L}\right)}{1+\left(\operatorname{SKINC}(i) S_{T}\right)} \times k m(i, 4)$,

sweat rate:

$$
m_{\mathrm{rsw}}(i)=\frac{\left[C_{\mathrm{sw}} \operatorname{Err}(1,1)+S_{\mathrm{sw}}(\mathrm{Wrms}-\mathrm{Clds})+P_{\mathrm{sW}} \operatorname{Wrm}(1,1) \mathrm{Wrms}\right] \times \operatorname{SKINS}(i) \times k m(i, 4)}{h_{f g}}
$$

where $\operatorname{BF}(i, j)$ is the skin blood flow rate, $\operatorname{BFB}(i, 4)$ is the basal blood flow rate, $m_{\mathrm{rsw}}$ is the regulatory sweating rate, $C_{\text {sw }}$ and $S_{\text {sw }}$ are sweating control coefficients of core and skin, $P_{\text {sw }}$ is the overall sweat control coefficient, $\operatorname{SHINC}(i)$, $\operatorname{SHINV}(i)$, and SKINS(i) are the weighting coefficients of sweating, vasodilatation, and vasoconstriction, $D_{L}$ and $S_{T}$ are the vasodilation and vasoconstriction signals, $k m(i, 4)$ is the local impact factor, $\operatorname{Err}(i, j)$ is the error signal, $\operatorname{Wrm}(1,1)$ is the warm signal, Wrms is the integrated warm signal, Clds is the integrated cold signal, and $h_{f g}$ is the evaporation heat of water.

Some important indicators are also presented:

$$
\begin{aligned}
T_{\text {core }} & =\overline{\sum_{i=1}^{6} T(i, 1)+T(25)} \\
T_{\text {skin }} & =\overline{\sum_{i=1}^{6} T(i, 4)} \\
M_{\mathrm{s}} & =\int \sum_{i=1}^{6} m_{\mathrm{rsw}}(i) d t,
\end{aligned}
$$

where $T_{\text {core }}$ is the mean core temperature of the body, $T_{\text {skin }}$ is the mean skin temperature of the body, and $M_{s}$ is the total sweat accumulation on skin surface.

Just as mentioned above, the cardiovascular system plays a key role in the thermal regulation process. The heart rate is directly affected by the thermoregulatory mechanism. In heart rate regulation, the metabolic rate and the core temperature are two important factors. In this paper, considering the heart rate regulation mechanism and its fluctuating rules, we propose a new heart rate simulation model. This model includes a quadratic function concerning core temperature and a nonlinear term concerning metabolic rate. The nonlinear term is used to simulate the great fluctuation caused by neuroregulation. The equation of the new heart rate regulation model is shown as follows:

$$
\mathrm{HR}=N(M)+T\left(T_{\text {core }}\right)
$$

where

$$
\begin{aligned}
N(M) & = \begin{cases}(k M+b)\left(1-\frac{1}{e^{c M t}}\right), & 0 \leq t \leq t_{0} \\
\frac{(k M+b)}{\left(e^{d\left(t-t_{0}\right) / M}\right)}, & t>t_{0}\end{cases} \\
T\left(T_{\text {core }}\right) & =p_{2} T_{\text {core }}^{2}+p_{1} T_{\text {core }}+p_{0} .
\end{aligned}
$$

The functions $N(M)$ and $T\left(T_{\text {core }}\right)$ account for the effect of the body's nervous regulation system and core temperature regulation on heart rate response, respectively. $M$ denotes the metabolic rate and it is an important indicator to reflect the exercise intensity. $T_{\text {core }}$ is the mean core temperature of all core nodes. $b, c, d, k, p_{2}, p_{1}$, and $p_{0}$ are function coefficients to be determined, all of which can be estimated in $[6,38]$.

3.2. Heat and Moisture Transfer Model of Clothing. Clothing plays an important role in providing thermal protection for the human body and creating a portable thermal microclimate between clothing and the human body. The heat and moisture transfer process in clothing is responsible for the temperature and humidity distributions and it directly affects the thermal performance of clothing. Heat conduction, heat convention, heat radiation, moisture absorption/desorption, and so forth are basic heat and moisture transfer ways. In this paper, heat and moisture transfer model of clothing used in the HCE system is referenced by some research reports $[32,33]$. The mathematic equations are described in Table 1.

In Table $1, \varepsilon_{a}, \varepsilon_{f}$, and $\varepsilon_{l}$ are the volume fractions of water vapor, fibers, and liquid water, respectively. $C_{a}$ is the water vapor concentration in the air. $\rho_{l}$ is the density of liquid water in the fibers. $C_{v}$ is the volumetric heat capacity of fabric. $T$ is the temperature of fabric. $K$ is the effective thermal conductivity of the fabric. $D_{f a b}$ is the water vapor diffusion ratio. $D_{l}$ is the liquid water diffusion ratio. $\Gamma_{R}$ is the heat radiation loss. $\Gamma_{f}$ is the effective sorption rate of the moisture. $\Gamma_{l g}$ is the evaporation (condensation) rate of liquid water (vapor). $\lambda_{v}$ and $\lambda_{l}$ are the heat sorption and desorption of vapor and liquid water. More detailed notations can be found in $[6,39]$.

Considering the heat and moisture interactions in the HCE system, the human body, clothing, and the environment 
TABLE 1: Heat and moisture transfer equations of clothing.

\begin{tabular}{|c|c|}
\hline Vapor moisture & $\frac{\partial\left(C_{a} \varepsilon_{a}\right)}{\partial t}=\frac{1}{\tau_{a}} \frac{\partial}{\partial x}\left(D_{a} \frac{\partial\left(C_{a} \varepsilon_{a}\right)}{\partial x}\right)-\omega_{1} \Gamma_{f}+\Gamma_{l g}$ \\
\hline Liquid moisture & $\frac{\partial\left(\rho_{l} \varepsilon_{l}\right)}{\partial t}=\frac{1}{\tau_{l}} \frac{\partial}{\partial x}\left(D_{l}\left(\varepsilon_{l}\right) \frac{\partial\left(\rho_{l} \varepsilon_{l}\right)}{\partial x}\right)-\omega_{2} \Gamma_{f}-\Gamma_{l g}$ \\
\hline Heat & $\begin{aligned} C_{v} \frac{\partial T}{\partial t}= & \frac{\partial}{\partial x}\left(K_{\text {mix }}(x) \frac{\partial T}{\partial x}\right)+\frac{\partial F_{R}}{\partial x}-\frac{\partial F_{L}}{\partial x}+ \\
& \omega_{2} \lambda_{v} \Gamma_{f}+\omega_{1} \lambda_{v} \Gamma_{f}-\lambda_{l} \Gamma_{l g}\end{aligned}$ \\
\hline Liquid diffusion & $D_{l}\left(\varepsilon_{l}\right)=\frac{\gamma \cos \theta \sin ^{2} \alpha d_{c} \varepsilon_{1}^{1 / 3}}{20 \eta \varepsilon^{1 / 3}}$ \\
\hline Condensation & $\Gamma_{l g}=\varepsilon_{a} h_{l g} S_{v}\left(C^{*}(T)-C_{a}\right)$ \\
\hline $\begin{array}{l}\text { Moisture } \\
\text { sorption }\end{array}$ & $\Gamma_{f}=\frac{\partial\left(C_{f} \varepsilon_{f}\right)}{\partial t}=\frac{1}{r} \frac{\partial}{\partial t}\left(r D_{f} \frac{\left(C_{f} \varepsilon_{f}\right)}{\partial r}\right)$ \\
\hline Radiation & $\frac{\partial F_{R}}{\partial x}=-\beta F_{R}+\beta \sigma T^{4}, \frac{\partial F_{L}}{\partial x}=\beta F_{L}-\beta \sigma T^{4}$ \\
\hline
\end{tabular}

are a coupled system in heat and moisture transfer. The boundary condition equations of the clothing heat and moisture models are accomplished by reference to the thermal status of the external environment and the body.

In practice, the interactive communications between clothing and the human body and clothing and the environment frequently happen by two boundaries. One is the boundary between the body skin and the inner layer of the clothing close to skin; the other is the boundary between the outer layers of the clothing exposed to the environment [40]. The clothing exchanges energy and moisture with the skin and the external environment, and the thermal status and physiological status are automatically updated.

For the inner side of the clothing close to the skin,

$$
\begin{aligned}
& -\left.\frac{D_{a}}{\tau_{a}} \frac{\partial\left(C_{a} \varepsilon_{a}\right)}{\partial x}\right|_{i, x=0}=\frac{p_{m} E(i, 4)}{\left(\lambda_{l g} S(i)\right)} \\
& -\left.\frac{D_{l}}{\tau_{l}} \frac{\partial\left(\rho_{l} \varepsilon_{l}\right)}{\partial x}\right|_{i, x=0}=\kappa_{2} \lambda_{l g} h_{l g}\left(C_{a}^{*}\left(T_{c l, 0}\right)-C_{a s k}(i)\right) \\
& -\left.K_{\text {mix }} \frac{d T}{d x}\right|_{i, x=0} \\
& =p_{m}\left(H_{t 1}\left(T_{c l, 0}-T(i, 4)\right)\right)+\frac{p_{h} E(i, 4)}{S(i)} \\
& +\kappa_{2} \lambda_{l g} h_{l g}\left(C_{a}{ }^{*}\left(T_{c l, 0}\right)-C_{a s k}(i)\right) .
\end{aligned}
$$

For the outer side of the clothing exposed to the environment,

$$
\begin{aligned}
& -\left.\frac{D_{a}}{\tau_{a}} \frac{\partial\left(C_{a} \varepsilon_{a}\right)}{\partial x}\right|_{i, x=L}=\kappa_{1} H_{m 2}\left(C_{a c l, L}-C_{\text {env }}\right) \\
& -\left.\frac{D_{l}}{\tau_{l}} \frac{\partial\left(\rho_{l} \varepsilon_{l}\right)}{\partial x}\right|_{i, x=L}=\kappa_{2} h_{l g}\left(C_{a}^{*}\left(T_{c l, L}\right)-C_{\text {env }}\right)
\end{aligned}
$$

$$
\begin{aligned}
-K_{\text {mix }} & \left.\frac{d T}{d x}\right|_{i, x=L} \\
= & \kappa_{2} \lambda_{l g} h_{l g}\left(C_{a}^{*}\left(T_{c l, L}\right)-C_{a \mathrm{env}}(i)\right) \\
& +H_{t 2}\left(T_{c l, L}-T_{\mathrm{env}}\right)
\end{aligned}
$$

where $p_{h}$ and $p_{m}$ are the proportions of moisture vapor and dry heat loss from skin at the clothing-covered area; $\kappa_{1}$ and $\kappa_{2}$ are the transfer proportions of water vapor and liquid water; $H_{t}$ is the heat conduction coefficient of air; $H_{m}$ is the mass transfer coefficient.

\section{An Exercise Thermophysiology Comfort Prediction Model}

Human comfort can be used to describe the overall state of the body physiologically, which is an important index of body wellbeing. Current researches on human comfort mainly focus on the unilateral prediction of thermal comfort. But, in reality, human thermal senses directly affect the physiological changes. For example, as the temperature of the human body rises, the heart rate, blood pressure, and other physiological signs will change as well. Therefore, the thermal comfort and physiological comfort should be integrated and taken into account. In this paper, an exercise thermophysiology comfort prediction model is designed. The fuzzy inference system [9] is used in the comfort prediction model. Some thermal and physiological indicators during exercise can be used as the input to predict the thermal comfort and health status.

For the various simulated indicators in our thermal physiological model, we select mean skin temperature, mean core temperature, and change rate of mean skin temperature as input variables, and the prediction results of thermal comfort will be got after the reasoning process. Correspondingly, we select the mean core temperature, sweat accumulation (it is approximately equal to the amount of dehydration), and heart rate as input variables and evaluate the physiological comfort. The comfort variables and the related fuzzy sets are listed in Table 2.

Equation (14) is the trapezoidal function, which is used to define the membership function of every input. The feeling interval for different thermal and physiological sensation can be obtained based on the trapezoidal function:

$$
\mu(x)= \begin{cases}\frac{x-a}{b-a}, & a \leq x \leq b \\ 1, & b \leq x \leq c \\ \frac{d-x}{d-c}, & c \leq x \leq d,\end{cases}
$$

where $a, b, c$, and $d$ are threshold parameters used to determine the shape of the membership function. By changing these parameters, the feeling interval of thermal and physiological status can be well defined and divided.

Figures 3 and 4 show the membership functions of thermal and physiological comfort inputs, respectively. All the 
TABLE 2: The list of comfort variables and the related fuzzy sets.

\begin{tabular}{lcc}
\hline Name & Variables & Fuzzy sets \\
\hline Thermal comfort $S_{l}$ & $T_{\text {skin }}$ & Very low, low, neutral, high, very high \\
& $T_{\text {core }}$ & Very low, low, neutral, high, very high \\
& $d T_{\text {skin }} / d t$ & Fast decrease, decrease, neutral, increase, fast increase \\
\hline Physiological comfort $S_{p}$ & $T_{\text {core }}$ & Very low, low, neutral, high, very high \\
& $M_{s}$ & Severe dehydration, moderate dehydration, slight dehydration, normal \\
& HR & Low, normal, high \\
\hline & $S_{l}$ & Cold, cool, neutral, warm, hot \\
Overall comfort $S$ & $S_{p}$ & High risk, low risk, normal \\
& $S$ & Uncomfortable, acceptable, comfortable
\end{tabular}

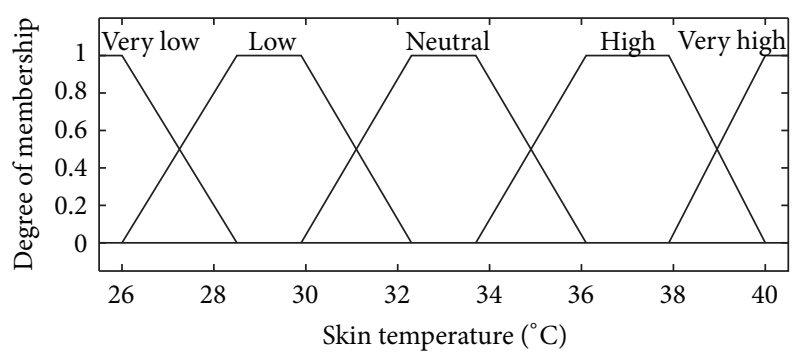

(a) Mean skin temperature

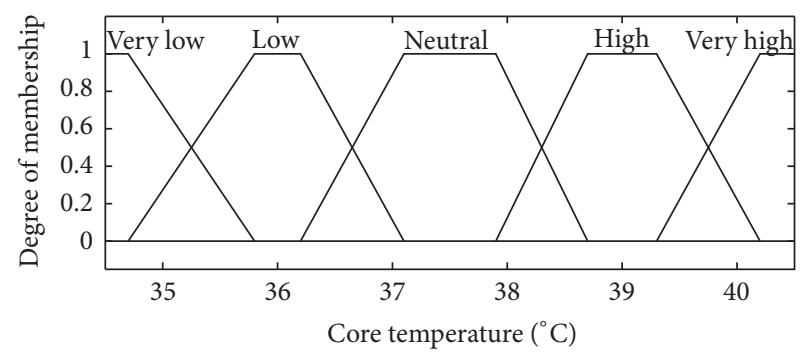

(b) Mean core temperature

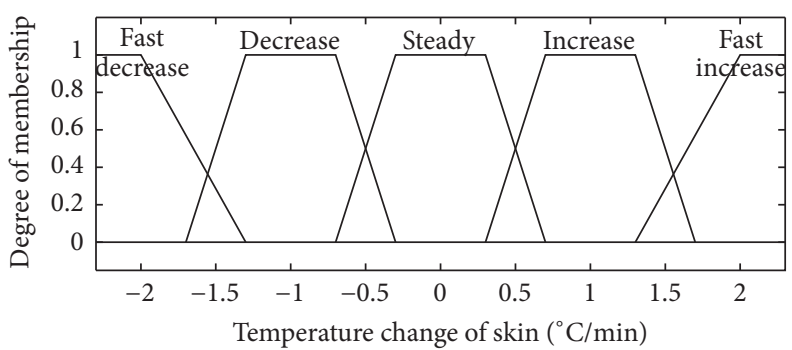

(c) Change rate of mean skin temperature

FIGURE 3: The membership function of thermal comfort indicators.

threshold parameters are given by experts on sports medicine [41].

According to the human mean skin temperature, mean core temperature, and change rate of mean skin temperature, we define a thermal comfort function to predict the human thermal status during exercise. In (15), $S_{l}$ is the thermal comfort sensation and $f$ is the thermal comfort inference function, in which an adaptive neurofuzzy inference system (ANFIS) is introduced to evaluate the thermal comfort. The ANFIS achieves fuzzification, fuzzy reasoning, and defuzzification process using a neutral work, while taking advantage of the information storage capacity and learning ability of artificial neural network [9]. Hence,

$$
S_{l}=f\left(T_{\text {skin }}, T_{\text {core }}, \frac{d T_{\text {skin }}}{d t}\right) .
$$

At the same time, physiological comfort of the human body should be considered. In accordance with the human mean core temperature, sweat accumulation, and heart rate, we define a physiological sensation function to predict the human health status during exercise. Equation (16) is the definition of physiological comfort sensation. In the physiological comfort inference process, we also construct the ANFIS to obtain the physiological comfort sensation. Hence,

$$
S_{p}=f\left(T_{\text {core }}, M_{s}, \mathrm{HR}\right) .
$$

Under a series of comfort inference rules, the overall comfort in (17) can be calculated from the thermal comfort sensation and physiological comfort sensation. All the rules defined here are based on a large number of statistical analyses and medicine knowledge $[6,33,41]$. Some representative inference rules defined in this paper are presented as follows:

$$
S=R\left(S_{l}, S_{p}\right)
$$

Rule 1. If thermal sensation is neutral and physiological sensation is normal, then overall comfort is comfortable. 


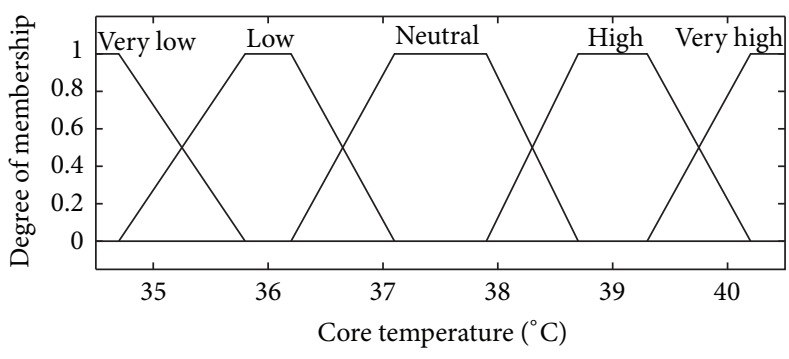

(a) Mean core temperature

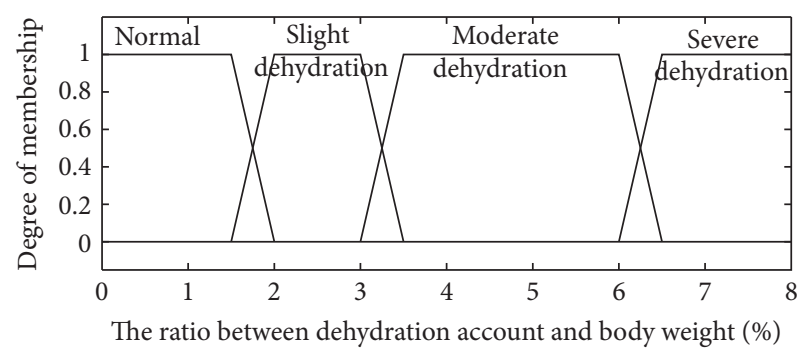

(b) Sweat accumulation

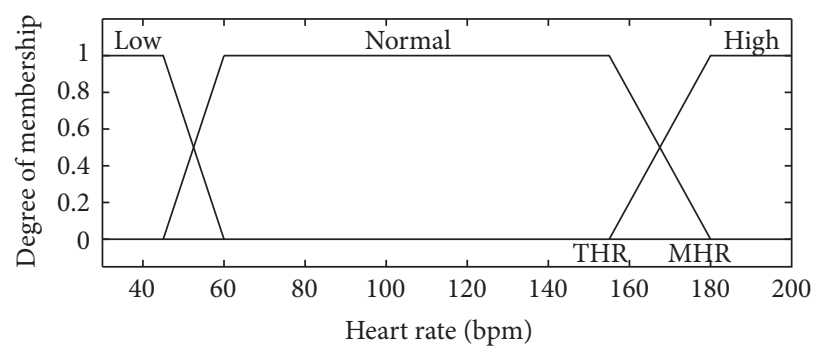

(c) Heart rate

FIGURE 4: The membership function of physiological comfort indicators.

TABle 3: Cases definition.

\begin{tabular}{|c|c|c|c|c|c|c|c|c|c|c|}
\hline \multirow[b]{3}{*}{ Case } & \multicolumn{10}{|c|}{ Settings } \\
\hline & \multicolumn{4}{|c|}{ Subject } & \multicolumn{2}{|c|}{ Clothing } & \multicolumn{2}{|c|}{ Environment } & \multicolumn{2}{|c|}{ Exercise } \\
\hline & Gender & $\begin{array}{c}\text { Age } \\
\text { (years) }\end{array}$ & $\begin{array}{c}\text { Weight } \\
(\mathrm{kg})\end{array}$ & $\begin{array}{c}\text { Body } \\
\text { area }\left(\mathrm{m}^{2}\right)\end{array}$ & Composition & $\begin{array}{c}\text { Coverage } \\
\text { rate }\end{array}$ & $\begin{array}{c}\text { Temperature } \\
\left({ }^{\circ} \mathrm{C}\right)\end{array}$ & $\begin{array}{l}\text { Relative } \\
\text { humidity }\end{array}$ & $\begin{array}{c}\text { Exercise } \\
\text { type }\end{array}$ & $\begin{array}{l}\text { Duration } \\
\text { (min) }\end{array}$ \\
\hline Case 1 & & & & & & & & & Running & 30 \\
\hline Case 2 & Male & 25 & 70 & 1.8 & $\begin{array}{c}98 \% \text { cotton, } 2 \% \\
\text { lycra }\end{array}$ & $70 \%$ & 32 & $50 \%$ & Jogging & 30 \\
\hline Case 3 & & & & & & & & & Walking & 30 \\
\hline
\end{tabular}

Rule 2. If thermal sensation is cool and physiological sensation is normal, then overall comfort is acceptable.

Rule 3. If thermal sensation is hot and physiological sensation is high risk, then overall comfort is uncomfortable.

\section{Case Study}

Three exercise cases are designed to evaluate the exercise thermophysiology comfort prediction model.

5.1. Scenes Setting. Different types of exercises are used for thermal physiological simulation and comfort prediction. Table 3 shows the cases definition. In the three cases, the subject is the same person ( 25 years old, $70 \mathrm{~kg}$, about $1.8 \mathrm{~m}^{2}$ body surface area). Also, the subject wears the same cotton suit with $70 \%$ coverage rate. The environment temperature and relative humidity are set to $32^{\circ} \mathrm{C}$ and $50 \%$. To set up several different scenes, three types of exercises for 30 minutes are introduced, that is, running, jogging, and walking.

\subsection{Results Discussion}

5.2.1. Simulation Results of Thermal Physiological Model. During exercise, the human body's thermal status and physiological status dynamically change, mainly reflected in the following phenomenon: temperature rising, heart rate accelerating, sweating increasing, and so forth. Figure 5 shows the simulated tendency curves of four important physiological indicators. It illustrates that the values of human physiological indicators are changed to varying degrees in different exercises. The higher the exercise intensity we choose, the more significant the changes in simulation.

Figure 5(a) illustrates the changes of mean core temperature in three scenes. Because of the thermoregulatory behaviors such as metabolic heat production, exercise heat production, and sweating, the core temperature increases gradually and it is maintained in balance within a certain temperature. Figure 5(b) illustrates the changes of mean skin temperature and Figure 5(c) illustrates the sweat accumulation of the human body. As shown in Figure 5(b), the values of mean skin temperature increase rapidly first and 


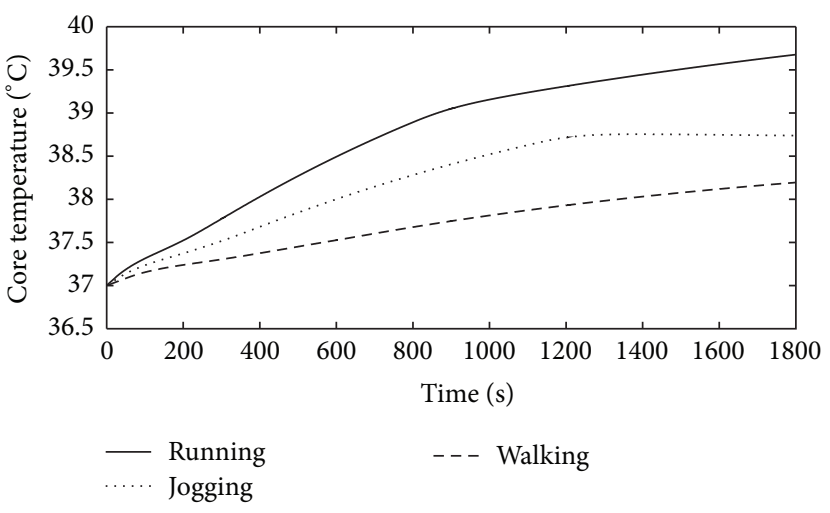

(a) Mean core temperature

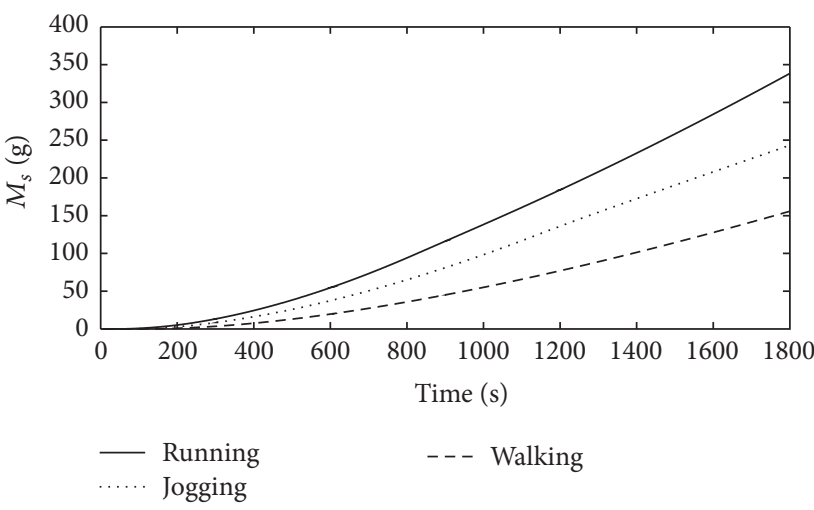

(c) Sweat accumulation

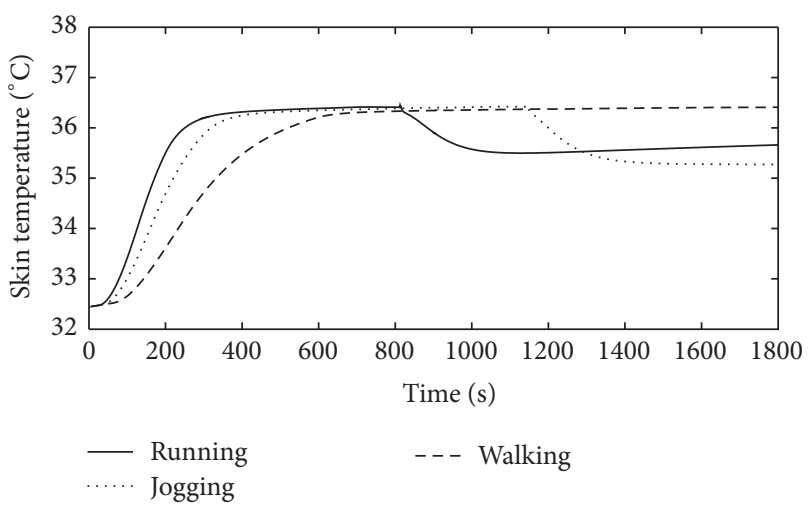

(b) Mean skin temperature

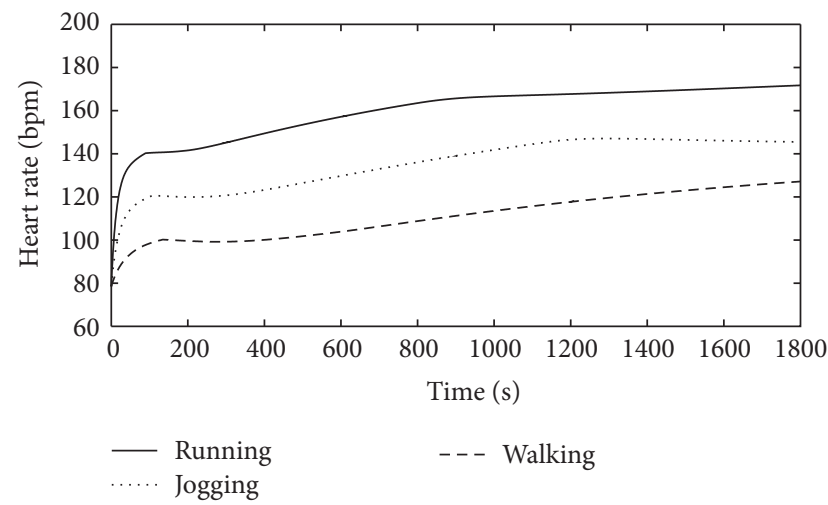

(d) Heart rate

Figure 5: The simulation results of our improved thermal physiological model in different scenes; they should be listed as (a) mean core temperature tendency, (b) mean skin temperature tendency, (c) sweat accumulation tendency, and (d) heart rate tendency.

then keep balance for a short time (especially in jogging and running) and at last decline to secondary balance state, while a relatively high skin temperature in walking continues for a long time. The variation of mean skin temperature is mainly due to the sweat evaporation of the human body, which can bring out heat from skin and decrease the skin temperature. Since the sweat in running is greater than that in jogging (reflected in Figure 5(c)), the mean skin temperature curve in running fell earlier than that in jogging in Figure 5(b). Meanwhile, the accumulation of sweat in walking affects the skin temperature slightly; thus, the tendency curve in walking increases first and then keeps balance. Figure 5(d) presents the changes of heart rate. As the heart rate simulation is directly associated with the core temperature and metabolic rate, its distribution is in agreement with the core temperature curves in Figure 5(a); running achieves the highest heart rate values, jogging is the second, and walking is the lowest.

5.2.2. Thermophysiology Comfort Prediction. Table 4 shows the simulated values and overall comfort in three different scenes. In general, walking makes people feel comfortable and acceptable in the whole process, while jogging makes people feel comfortable and acceptable in a relatively long period of time, and running makes people feel uncomfortable in a relatively long period of time.
In the first $166 \mathrm{~s}$ of case 1 , people feel comfortable, since all thermal sensation and physiological sensation keep normal. From 167 s to 513 s, people feel acceptable since thermal sensation changes to warm, but physiological sensation still keeps normal. After that, from $514 \mathrm{~s}$, both the thermal values and the physiological values are changed; people feel uncomfortable with the thermal sensation getting into hot and physiological sensation getting into low risk and even high risk. In case 2, from $0 \mathrm{~s}$ to $213 \mathrm{~s}$, people feel comfortable since both thermal sensation and physiological sensation are normal. From $214 \mathrm{~s}$ to $815 \mathrm{~s}$, the human comfort is acceptable. From $816 \mathrm{~s}$, people feel uncomfortable with the thermal sensation getting into hot and physiological sensation getting into low risk. In case 3 , from $0 \mathrm{~s}$ to $320 \mathrm{~s}$, people feel comfortable. After that, people feel acceptable until the end of the exercise.

The experiment results show some important and valuable suggestions: for example, walking is a comfortable and acceptable exercise in daily life; our simulated results also tell us that walking within 30 minutes is acceptable and cannot cause any discomfort. Jogging for a relatively long period of time also makes people feel comfortable, while it will make people feel uncomfortable when the exercise time exceeds 13.5 minutes. Therefore, we should pay attention to drinking water and cooling while jogging for a long time. The results also show that running will easily cause body discomfort. When people run at $32^{\circ} \mathrm{C}$ in 8 minutes, it is easy 
TABLE 4: Results of thermophysiology comfort prediction for three cases.

\begin{tabular}{|c|c|c|c|c|}
\hline Cases & Time (seconds) & $\begin{array}{c}\text { Thermal values } \\
T_{\text {skin }} / T_{\text {core }} / d T_{\text {skin }} / d t / S_{l} \\
\left({ }^{\circ} \mathrm{C} /{ }^{\circ} \mathrm{C} /{ }^{\circ} \mathrm{C} /-\right)\end{array}$ & $\begin{array}{c}\text { Physiological values } \\
T_{\text {core }} / M_{s} / \mathrm{HR} / S_{p} \\
\left({ }^{\circ} \mathrm{C} / \mathrm{g} /-/-\right)\end{array}$ & Overall comfort \\
\hline \multirow{6}{*}{ Case 1} & $t=0$ & $32.44 / 36.99 / 0.44 /$ neutral & 36.99/0.00/78.49/normal & Comfortable \\
\hline & $t=166$ & $34.89 / 37.44 / 2.89 /$ neutral & 37.44/3.22/140.95/normal & Comfortable \\
\hline & $t=167$ & 34.91/37.45/2.91/warm & 37.45/3.27/140.97/normal & Acceptable \\
\hline & $t=513$ & 36.36/38.29/4.36/warm & $38.29 / 40.22 / 153.93 /$ normal & Acceptable \\
\hline & $t=514$ & $36.36 / 38.30 / 4.36 /$ hot & 38.30/40.37/153.97/low risk & Uncomfortable \\
\hline & $t=1800$ & $35.66 / 39.67 / 3.66 /$ hot & 39.67/338.35/171.69/high risk & Uncomfortable \\
\hline \multirow{6}{*}{ Case 2} & $t=0$ & $32.44 / 36.99 / 0.44 /$ neutral & $36.99 / 0.00 / 78.49 /$ normal & Comfortable \\
\hline & $t=213$ & $34.88 / 37.38 / 2.88 /$ neutral & 37.38/3.52/119.90/normal & Comfortable \\
\hline & $t=214$ & $34.90 / 37.39 / 2.90 /$ warm & 37.39/3.57/119.90/normal & Acceptable \\
\hline & $t=815$ & 36.38/38.29/4.38/warm & 38.29/67.36/136.49/normal & Acceptable \\
\hline & $t=816$ & $36.38 / 38.30 / 4.38 /$ hot & 38.30/67.51/136.52/low risk & Uncomfortable \\
\hline & $t=1800$ & $35.27 / 38.73 / 3.27 /$ hot & 38.73/243.23/145.43/low risk & Uncomfortable \\
\hline \multirow{4}{*}{ Case 3} & $t=0$ & $32.44 / 36.99 / 0.44 /$ neutral & 36.99/0.00/78.49/normal & Comfortable \\
\hline & $t=320$ & 34.89/37.31/2.89/neutral & 37.31/4.16/99.28/normal & Comfortable \\
\hline & $t=321$ & 34.90/37.31/2.90/warm & 37.31/4.20/99.29/normal & Acceptable \\
\hline & $t=1800$ & 36.41/38.19/4.41/warm & $38.19 / 155.83 / 127.12 /$ normal & Acceptable \\
\hline
\end{tabular}

for them to feel uncomfortable. Running makes people feel uncomfortable by changing body temperature into a hot state and putting the human body's physiological state into a high risk state. So, we recommend not to run for a long time in a hot environment.

5.3. More Discussion. The aim of the case study is to evaluate human comfort under different exercise intensities. Therefore, we take exercise intensity as variable, and other factors (subject, clothing, environment, etc.) as invariants in the setting of the case study. It is worth noting that this does not mean that our model cannot simulate the thermal physiological changes and predict human comfort caused by other factors. To support this conclusion, some extra cases are discussed as follows.

(i) Subject. To validate that our model is subject-sensitive, subjects of different gender, age, and body type have been chosen and series cases are designed and simulated. From the simulation results, it can be concluded that different personal parameter settings can affect the human thermoregulatory mechanism and cause different degrees of thermal physiological and human comfort change. For example, core temperature, sweat accumulation, and heart rate in old people are lower than those in young people. Besides, old people are more likely to feel uncomfortable. Parts of the simulated tendency curves such as mean skin temperature and sweat accumulation are shown in Figure 6. Therefore, our simulation is subject-sensitive.

(ii) Clothing. To validate that our model is clothing-sensitive, a series of contrast experiments with different clothing settings are conducted, and parts of the simulated tendency curves such as mean core temperature and sweat accumulation are shown in Figure 7.

(iii) Environment. To validate that our model is environmentsensitive, we also conduct a series of contrast experiments with different environment settings. The result shows that a man running in an extreme environment like high temperature and high humidity can easily experience discomfort both in thermal sensation and in physiological sensation. Figure 8 shows the tendency curves and Table 5 lists the predicted comfort.

Although we have not elaborated the effects of subject, clothing, and environment on human thermal physiological simulation as well as comfort prediction, our thermal physiological model and comfort prediction model are capable of simulating and analyzing the effects caused by these factors in HCE systems.

\section{A Mobile Application for Human Comfort Prediction}

With the development of mobile communication technology and increasing popularization of the Internet, mobile multimedia services are more and more favored by users. Various mobile devices and applications are designed to aid people to improve their life quality. Exercise thermophysiology comfort is regarded as one of the most important and significative research areas, which has been focused upon in recent years. According to the previous description and the mobile application requirements of human comfort, a user-friendly smart application with low computational requirements has been developed to evaluate human exercise comfort in daily 


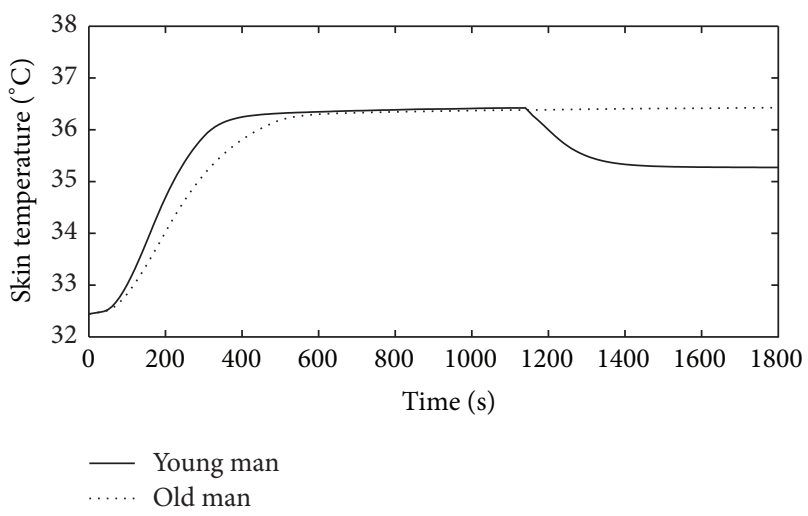

(a) Mean skin temperature

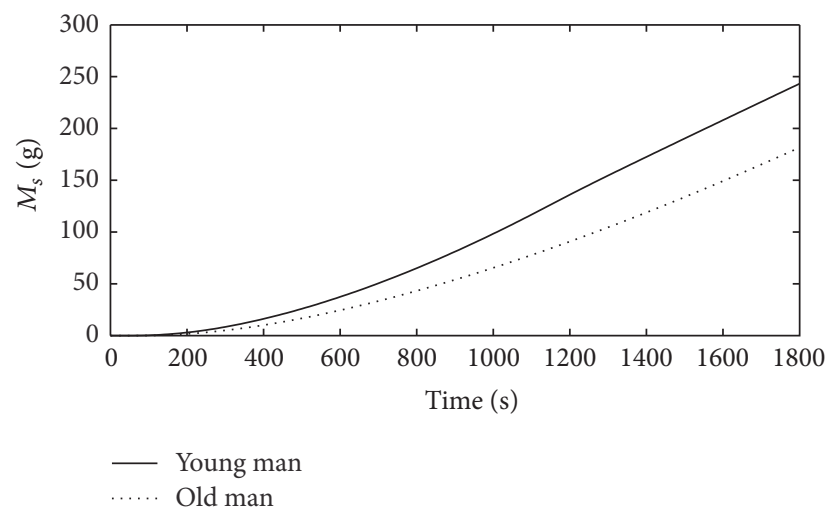

(b) Sweat accumulation

Figure 6: The tendency curves of mean skin temperature and sweat accumulation with different subjects.

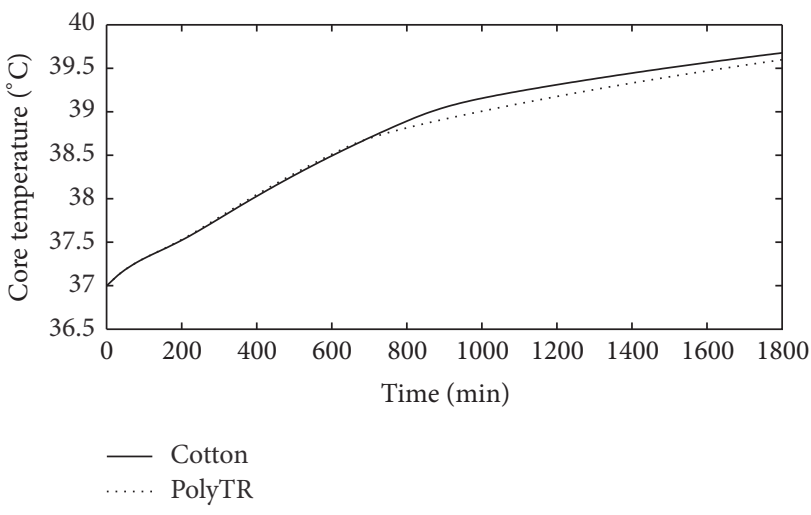

(a) Mean core temperature

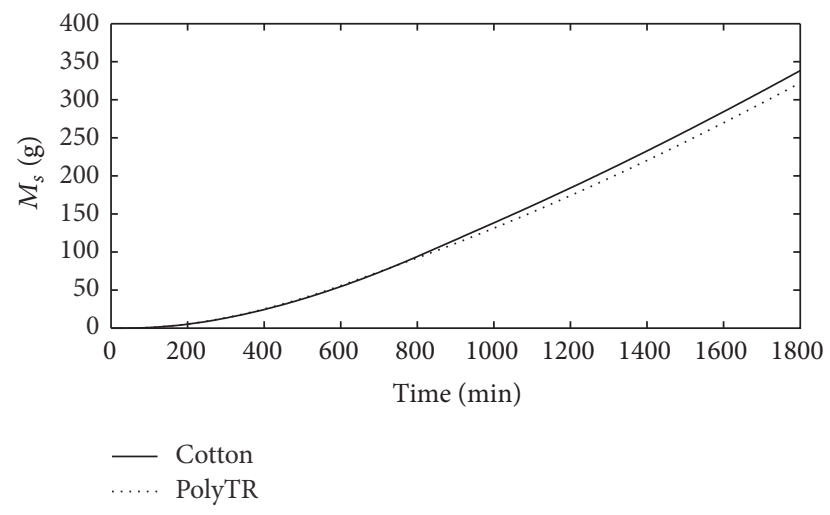

(b) Sweat accumulation

FIGURE 7: The tendency curves of mean core temperature and sweat accumulation with different clothing.

TABLE 5: Results of thermophysiology comfort prediction in different environments.

\begin{tabular}{|c|c|c|c|c|}
\hline Cases & $\begin{array}{c}\text { Time } \\
\text { (seconds) }\end{array}$ & $\begin{array}{c}\text { Thermal values } \\
T_{\text {skin }} / T_{\text {core }} / d T_{\text {skin }} / d t / S_{l} \\
\left({ }^{\circ} \mathrm{C} /{ }^{\circ} \mathrm{C} /{ }^{\circ} \mathrm{C} /-\right)\end{array}$ & $\begin{array}{c}\text { Physiological values } \\
T_{\text {core }} / M_{s} / \mathrm{HR} / S_{p} \\
\left({ }^{\circ} \mathrm{C} / \mathrm{g} /-/-\right)\end{array}$ & Overall comfort \\
\hline \multirow{6}{*}{$25^{\circ} \mathrm{C}, 50 \% \mathrm{RH}$} & $t=0$ & $31.67 / 37.01 /-0.32 /$ neural & 37.01/0.00/79.19/normal & Comfortable \\
\hline & $t=302$ & $34.90 / 37.44 / 2.90 /$ neural & 37.44/5.88/117.47/normal & Comfortable \\
\hline & $t=303$ & $34.90 / 37.44 / 2.91 /$ warm & 37.44/5.93/117.48/normal & Acceptable \\
\hline & $t=1087$ & 35.92/38.30/3.92/warm & 38.30/87.40/133.78/normal & Acceptable \\
\hline & $t=1088$ & $35.92 / 38.30 / 3.92 /$ hot & 38.30/87.55/133.80/low risk & Uncomfortable \\
\hline & $t=1800$ & 35.96/38.77/3.96/hot & $38.77 / 210.52 / 146.46 /$ low risk & Uncomfortable \\
\hline \multirow{6}{*}{$35^{\circ} \mathrm{C}, 70 \% \mathrm{RH}$} & $t=0$ & $32.88 / 37.04 / 0.88 /$ neutral & $37.04 / 0.00 / 80.31 /$ normal & Comfortable \\
\hline & $t=162$ & $34.89 / 37.36 / 2.89 /$ neutral & $37.36 / 2.66 / 121.68 /$ normal & Comfortable \\
\hline & $t=163$ & 34.91/37.36/2.91/warm & $37.36 / 2.70 / 121.68 /$ normal & Acceptable \\
\hline & $t=713$ & $36.60 / 38.30 / 4.60 /$ warm & 38.30/61.56/138.11/normal & Acceptable \\
\hline & $t=714$ & $36.60 / 38.30 / 4.60 /$ hot & 38.30/61.72/138.14/low risk & Uncomfortable \\
\hline & $t=1800$ & $36.60 / 39.30 / 4.60 /$ hot & 39.30/299.33/160.91/low risk & Uncomfortable \\
\hline
\end{tabular}




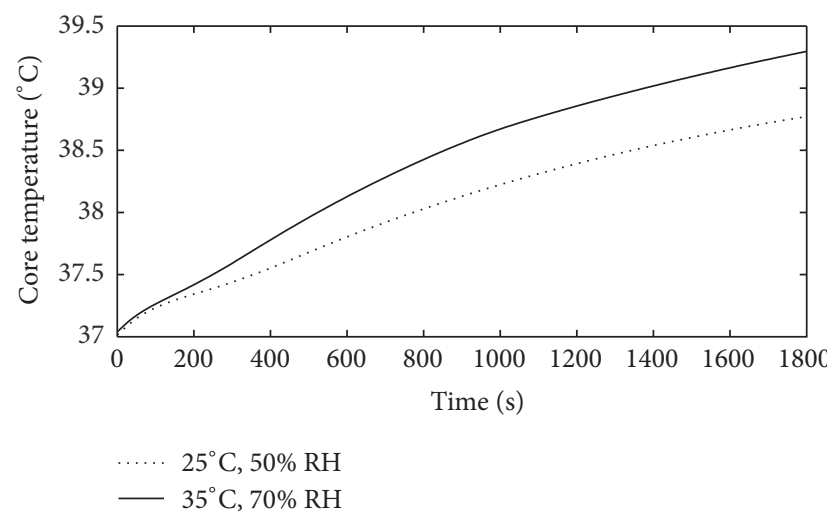

(a) Mean core temperature

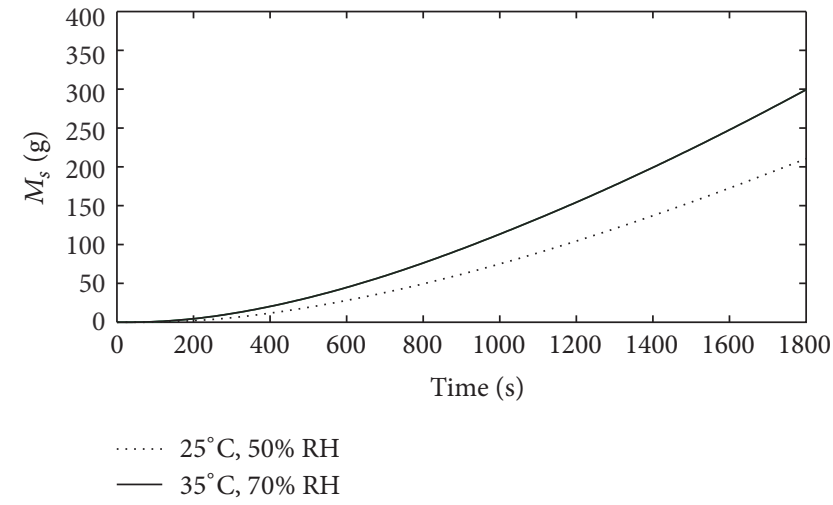

(b) Sweat accumulation

FIGURE 8: The tendency curves of mean core temperature and sweat accumulation with different environments.

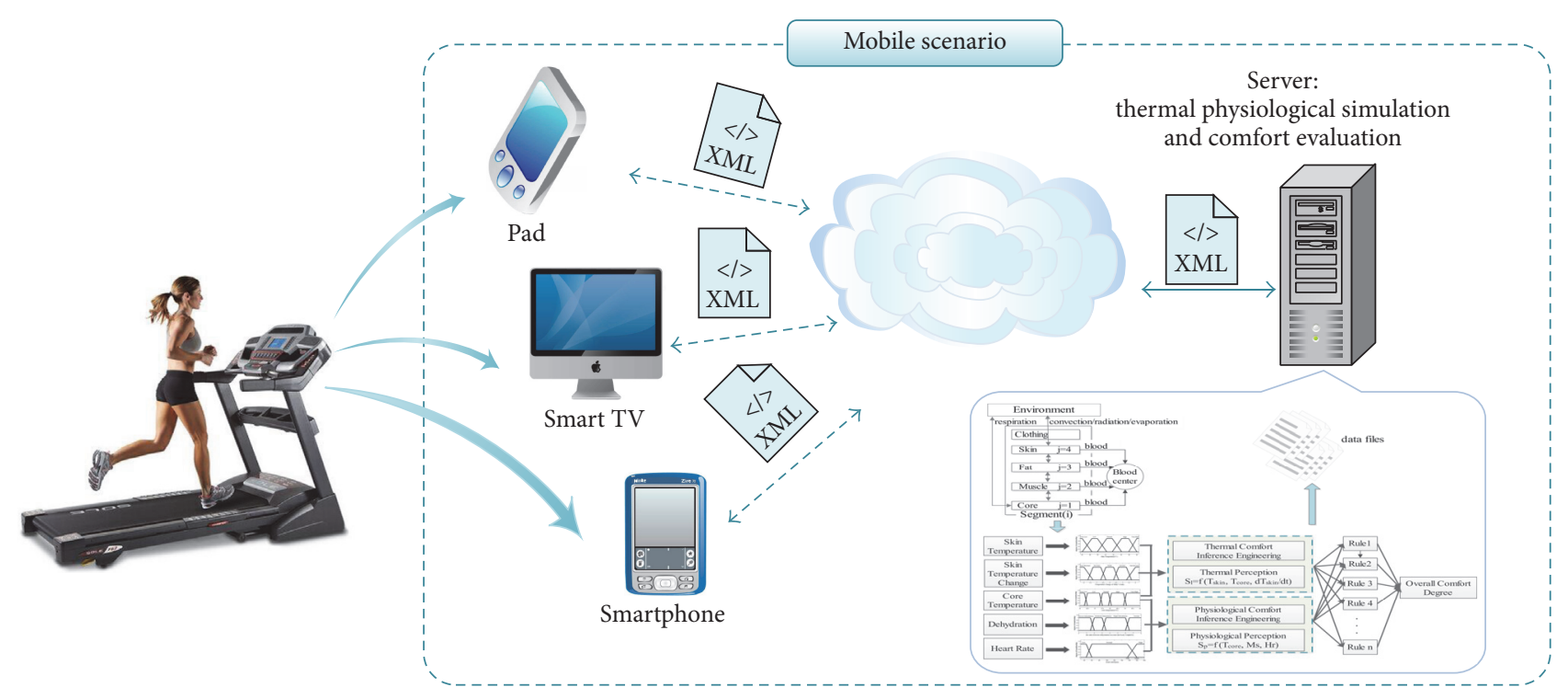

FIGURE 9: The basic architecture for the comfort prediction prototype in mobile scenario.

life, which allows easily changing the simulation scenes and simulating the human physiological status as well as carrying out comfort evaluation and prediction. The basic architecture for the prototype is shown in Figure 9. Through a variety of mobile devices, the scene parameters are set and transmitted to the server side to compute the comfort sensation of the human body.

6.1. App Input: Scene Parameters Definition. Various parameters in the scene of case study directly affect simulation results, and the different combination of scene parameters will produce different physiological state and comfort sensation. Four main types of scene parameters are defined, which are personal parameter, clothing parameter, activity parameter, and boundary parameter. Figure 10(a) shows the list view of scene parameters, and Figures 10(b) and 10(c) are the detailed views. The personal parameter includes the gender, age, height, weight, and some specific human physiological parameters like the density of blood and specific heat of the body. Because these physiological parameters have small variations among individuals, they are preset with default values. If necessary, these specific physiological parameters can be input by customs themselves. The clothing parameter includes the clothing style, composition, and coverage rate. Besides, the fabric parameters like porosity, capillary angle, and heat transfer coefficients are also preset. The activity parameter contains environment and exercise settings. Temperature, humidity, wind velocity, and exercise type and duration are all considered. The boundary parameter defines some interactive information of HCE systems, such as skin temperature and inner garment temperature.

6.2. Server: Physiological Simulation and Comfort Prediction. Server side is used to handle the time-consuming and computing resource-intensive simulation task in HCE system. It takes scene parameters as input and outputs the body comfort sensation. 


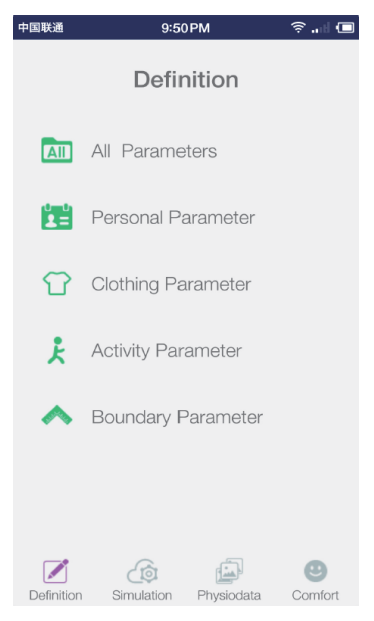

(a) Scene definition

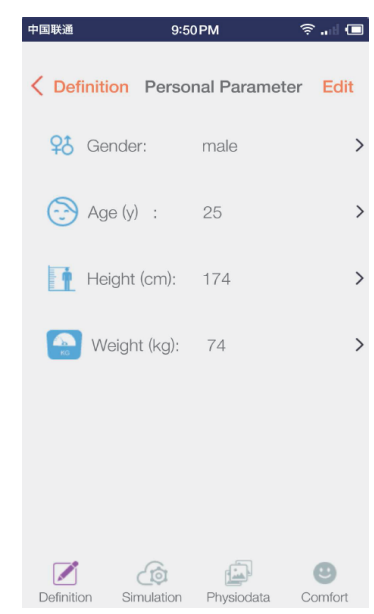

(b) Personal parameter

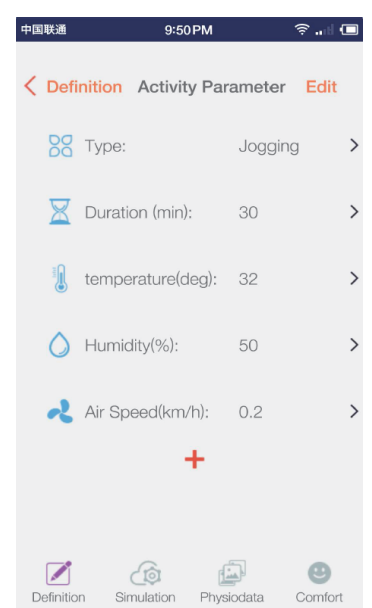

(c) Activity parameter

FIgURE 10: The scene definition views of the app.

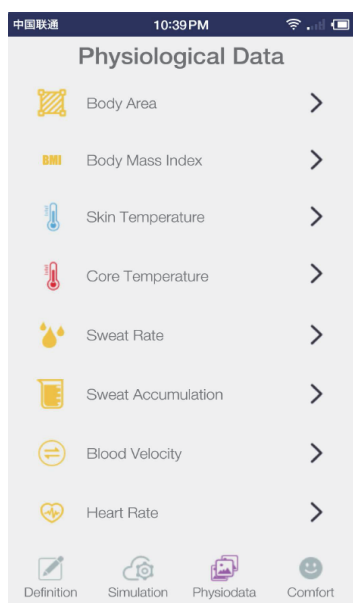

(a) Physiological data list

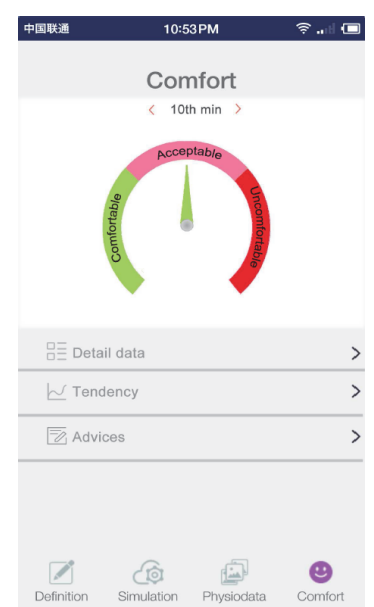

(b) Comfort result

FIgURE 11: The views of simulation results.

The server receives input parameters from clients, and then numerical solutions are taken to solve the human physiological model, heat and moisture transfer model, and the interactive equations between body and clothing. After that, the server uses the simplified neurofuzzy inference system to carry out comfort evaluation and prediction. The simulated results such as human skin temperature, heart rate, sweat rate, and comfort sensation are generated. At last, all these results are transferred back to the smart devices. The data transmission between the client and the server is encapsulated as a customized file in XML format.

6.3. App Output: Results Visualization. A variety of graphical representations are used in our application to help users visualize the change of physiological state and comfort sensation. Figure 11 shows the visualization screenshots of the app (corresponding to "Physiodata" in Figure 11(a) and "Comfort" in Figure 11(b)). Figure 11(a) shows the calculated physiological data, and Figure 11(b) displays the overall comfort sensation. The detailed information of comfort sensation can be obtained, and also some pieces of advice related to exercise comfort sensation are given.

\section{Conclusion}

During exercise, the heat balance of the human body is maintained by the processes of heat production and heat loss via radiation, conduction, convection, and evaporation. These processes would have effects on the physiological responses and influence the thermal status and comfort perception. In order to predict human thermophysiology comfort, in this paper, a heart rate regulation model is added to HCE system to simulate the human body thermal physiological behavior; according to this improved model, some important physiological parameters can be obtained. Further, in this paper, a novel thermophysiology comfort prediction model and a user-friendly mobile application for human comfort prediction are designed. The experiment results show that 
there is the same prediction trend on the experiment result and simulation result about thermophysiology comfort. The proposed exercise thermophysiology comfort prediction model still has some limitation. The thermal physiological mechanism needs to be researched to simulate the human physiological sensation further. We need to achieve and analyze more exercises and even investigate how to apply this simulation model and comfort model in the health services.

\section{Nomenclature}

$\beta$ : $\quad$ Radiation absorption constant of the fiber $\left(\mathrm{m}^{-1}\right)$

$\varepsilon: \quad$ Porosity of the fabric

$\varepsilon_{a}: \quad$ Volume fraction of water vapor

$\varepsilon_{f}: \quad$ Volume fraction of fibers

$\varepsilon_{l}: \quad$ Volume fraction of liquid phase

$\eta$ : $\quad$ Dynamic viscosity of liquid $(\mathrm{kg} / \mathrm{ms})$

$\gamma: \quad$ Surface tension of fiber $(\mathrm{J} / \mathrm{m})$

$\Gamma_{f}$ : $\quad$ Effective sorption rate of the moisture

$\Gamma_{l g}: \quad$ Evaporation/condensation rate of the liquid/vapor

$\lambda_{l}$ : $\quad$ Heat of sorption or desorption of liquid by fibers $(\mathrm{kJ} / \mathrm{kg})$

$\lambda_{v}$ : $\quad$ Heat of sorption or desorption of vapor by fibers $(\mathrm{kJ} / \mathrm{kg})$

$\rho_{l}: \quad$ Density of the liquid water $\left(\mathrm{kg} / \mathrm{m}^{3}\right)$

$\sigma: \quad$ Stefan-Boltzmann constant $\left(\mathrm{W} / \mathrm{m}^{2} \mathrm{~K}\right)$

$\tau_{a}$ : $\quad$ Effective tortuosity of the fabric for water vapor diffusion

$\theta$ : $\quad$ Contact angle of the liquid water on the fiber surface

$B(i, j)$ : Heat transfer by blood flow in node $(i, j)$ (W)

$\mathrm{BF}(i, j): \quad$ Blood flow rate of node $(i, j)(1 / \mathrm{h})$

$\operatorname{BFB}(i, j)$ : Basal blood flow rate of node $(i, j)(1 / \mathrm{h})$

$C(25): \quad$ Thermal capacity of the blood $\left(\mathrm{Wh} /{ }^{\circ} \mathrm{C}\right)$

$C(i, j): \quad$ Thermal capacity in node $(i, j)\left(\mathrm{Wh} /{ }^{\circ} \mathrm{C}\right)$

$C^{*}(T): \quad$ Saturated water vapor concentration at $T$ $\left(\mathrm{kg} / \mathrm{m}^{3}\right)$

$C_{a}$ : Water vapor concentration in the air filling the interfiber void space $\left(\mathrm{kg} / \mathrm{m}^{3}\right)$

$C_{h}(i, j)$ : Shivering metabolic heat generation in node $(i, j)(\mathrm{W})$

$C_{v}$ : $\quad$ Volumetric heat capacity of the fabric $\left(\mathrm{kJ} / \mathrm{m}^{3} \mathrm{~K}\right)$

Chilf(i): Weighting and distribution coefficient of shivering muscles

$\operatorname{Cld}(i, j):$ Cold signal of node $(i, j)$

Clds: Integrated cold signal of the whole skin surface

$D(i, j)$ : Heat transfer by thermal conduction in node $(i, j)(\mathrm{W})$

$D_{a}$ : Diffusion coefficient of water vapor in the air of the fabric $\left(\mathrm{m}^{2} / \mathrm{s}\right)$

$D_{f}$ : Diffusion coefficient of water vapor in the fibers of the fabric $\left(\mathrm{m}^{2} / \mathrm{s}\right)$

$D_{L}$ : Control signal of vasodilation
$D_{l}$ : $\quad$ Diffusion coefficient of liquid water in the fibers of the fabric $\left(\mathrm{m}^{2} / \mathrm{s}\right)$

$E(i, j)$ : Heat loss by evaporation through the skin surface in node $(i, j)(\mathrm{W})$

$\operatorname{Err}(i, j): \quad$ Error signal of node $(i, j)$

$F_{L / R}: \quad$ Elementary total thermal radiation incident inside the clothing travelling to the left/right $\left(\mathrm{W} / \mathrm{m}^{2}\right)$

$h_{c}$ : $\quad$ Convection heat transfer coefficient $\left(\mathrm{W} / \mathrm{m}^{2} \mathrm{~K}\right)$

$h_{r}: \quad$ Radiation heat transfer coefficient $\left(\mathrm{W} / \mathrm{m}^{2} \cdot{ }^{\circ} \mathrm{C}\right)$

$h_{t}(i): \quad$ Integrated heat transfer coefficient $\left(\mathrm{W} / \mathrm{m}^{2} \cdot{ }^{\circ} \mathrm{C}\right)$

$h_{f g}: \quad$ Evaporation heat of water $(\mathrm{J} / \mathrm{kg})$

$h_{l \leftrightarrow g}$ : $\quad$ Mass transfer coefficient for evaporation and condensation $(\mathrm{m} / \mathrm{s})$

$k_{a}$ : Thermal conductivity of the air $\left(\mathrm{mmW} / \mathrm{m}^{2} \cdot{ }^{\circ} \mathrm{C}\right)$

$K_{\text {mix }}$ : $\quad$ Effective thermal conductivity of the fabric $(\mathrm{W} / \mathrm{m} / \mathrm{K})$

$k m(i, 4): \quad$ Regional influence factor

$m_{s}(i)$ Sweating accumulation on the skin surface in the $i$ th part $\left(\mathrm{g} / \mathrm{m}^{2}\right)$

$m_{\text {rsw }}(i)$ : Regulatory sweating in the $i$ th part $\left(\mathrm{g} / \mathrm{s} / \mathrm{m}^{2}\right)$

$P_{\mathrm{ea}}(i): \quad$ Water vapor pressure of ambient temperature in the ith part $(\mathrm{Pa})$

$P_{\text {sat }}(i)$ Saturation water vapor pressure on the skin temperature in the $i$ th part $(\mathrm{Pa})$

$P_{\text {sk }}(i)$ Water vapor pressure on the skin surface in the $i$ th part $(\mathrm{Pa})$

$Q(i, j): \quad$ Metabolic heat generation in node $(i, j)$ (W)

$Q_{b}(i, j): \quad$ Basal metabolic heat generation in node $(i, j)(\mathrm{W})$

$Q_{t}(i, j): \quad$ Heat loss by convection and thermal radiation in node $(i, j)(\mathrm{W})$

$r: \quad$ Radius (mm)

$R_{\mathrm{ea}}(i): \quad$ Evaporation heat resistance on the skin surface in the $i$ th part $\left(\mathrm{m}^{2} \mathrm{~Pa} / \mathrm{W}\right)$

$R_{\text {esk }}(i)$ Evaporation resistance of the skin in the $i$ th part $\left(\mathrm{m}^{2} \mathrm{~Pa} / \mathrm{W}\right)$

$\operatorname{RES}(i, 1)$ : Latent respiration heat loss in node $(i, 1)$ (W)

$R T(i, 4): \quad$ Width of temperature

$S_{T}$ : Control signal of vasoconstriction

$S_{v}: \quad$ Surface-to-volume ratio of the fiber $\left(\mathrm{m}^{-1}\right)$

SKINC(i): Weighting and distribution coefficient of vasoconstriction in the $i$ th part

SKINR(i): Integrated weight coefficient

SKINS(i): Weighting and distribution coefficient of sweating in the $i$ th part

SKINV(i): Weighting and distribution coefficient of vasodilation in the $i$ th part

$T: \quad$ Temperature of the fabric $(\mathrm{K})$

T(25): $\quad$ Temperature of the blood $\left({ }^{\circ} \mathrm{C}\right)$

$T(i, j): \quad$ Temperature of node $(i, j)(\mathrm{K})$ 
$t_{a I}: \quad$ Thickness of the air layer $(\mathrm{mm})$

$T_{\text {set }}(i, j)$ : The set-point temperature of node $(i, j)$ $\left({ }^{\circ} \mathrm{C}\right)$

$W(i, j): \quad$ Work accomplished in node $(i, j)(W)$

$\operatorname{Wrm}(i, j)$ : Warm signal of node $(i, j)$

Wrms: Integrated warm signal of the whole skin surface.

\section{Competing Interests}

The authors declare no competing interests.

\section{Acknowledgments}

This research is supported by the National Natural Science Foundation of China (NSFC) (nos. 61320106008, 61402185, and 61672547).

\section{References}

[1] K. R. Miller, S. A. McClave, M. B. Jampolis et al., "The health benefits of exercise and physical activity," Current Nutrition Reports, vol. 5, no. 3, pp. 204-212, 2016.

[2] E. Anderson and G. Shivakumar, Effects of exercise and physical activity on anxiety. Progress in Physical activity and Exercise and Affective and Anxiety Disorders: Translational Studies, Perspectives and Future Directions, 2015.

[3] S. M. Phillips, T. R. Wójcicki, and E. McAuley, "Physical activity and quality of life in older adults: an 18-month panel analysis," Quality of Life Research, vol. 22, no. 7, pp. 1647-1654, 2013.

[4] K. Okazaki, "Body temperature regulation during exercise training," in Musculoskeletal Disease Associated with Diabetes Mellitus, pp. 253-268, Springer, Berlin, Germany, 2016.

[5] J.-K. Davis and P. A. Bishop, "Impact of clothing on exercise in the heat," Sports Medicine, vol. 43, no. 8, pp. 695-706, 2013.

[6] J. Jiao, Effects of clothing on running physiology and performance in a hot condition [Ph.D. thesis], The Hong Kong Polytechnic University, 2014.

[7] R. J. Dear, T. Akimoto, E. A. Arens et al., "Progress in thermal comfort research over the last twenty years," Indoor Air, vol. 23, no. 6, pp. 442-461, 2013.

[8] A. K. Mishra and M. Ramgopal, "Field studies on human thermal comfort-an overview," Building and Environment, vol. 64, pp. 94-106, 2013.

[9] R. Wang, H. Du, F. Zhou, D. Deng, and Y. Liu, "An adaptive neural fuzzy network clothing comfort evaluation model and application in digital home," Multimedia Tools and Applications, vol. 71, no. 2, pp. 395-410, 2014.

[10] B. R. M. Kingma, L. Schellen, A. J. H. Frijns, and W. D. van Marken Lichtenbelt, "Thermal sensation: a mathematical model based on neurophysiology," Indoor Air, vol. 22, no. 3, pp. 253262, 2012.

[11] C. Huizenga, Z. Hui, and E. Arens, "A model of human physiology and comfort for assessing complex thermal environments," Building and Environment, vol. 36, no. 6, pp. 691-699, 2001.

[12] P. Senthilkumar, "Heat and moisture transfer in textiles," in Man-Made Textiles in India, p. 43, 2015.

[13] M. Fu, T. Yu, H. Zhang, W. Weng, and H. Yuan, "Heat and moisture transfer through clothing for a person with contact surface," in Proceedings of the 13th International Conference on
Indoor Air Quality and Climate, Indoor Air, pp. 100-107, Hong Kong, July 2014.

[14] P. S. H. Henry, "The diffusion of moisture and heat through textiles," Discussions of the Faraday Society, vol. 3, pp. 243-257, 1948.

[15] B. Farnworth, "Mechanisms of heat flow through clothing insulation," Textile Research Journal, vol. 53, no. 12, pp. 717-725, 1983.

[16] Y. Li and B. V. Holcombe, "A two-stage sorption model of the coupled diffusion of moisture and heat in wool fabrics," Textile Research Journal, vol. 62, no. 4, pp. 211-217, 1992.

[17] Y. Li and Z. Luo, "An improved mathematical simulation of the coupled diffusion of moisture and heat in wool fabric," Textile Research Journal, vol. 69, no. 10, pp. 760-768, 1999.

[18] Y. Lu, G. Song, H. Zeng, L. Zhang, and J. Li, "Characterizing factors affecting the hot liquid penetration performance of fabrics for protective clothing," Textile Research Journal, vol. 84, no. 2, pp. 174-186, 2014

[19] M. Fu, M. Q. Yuan, and W. G. Weng, "Modeling of heat and moisture transfer within firefighter protective clothing with the moisture absorption of thermal radiation," International Journal of Thermal Sciences, vol. 96, pp. 201-210, 2015.

[20] N. Sarier and E. Onder, "Organic phase change materials and their textile applications: an overview," Thermochimica Acta, vol. 540, pp. 7-60, 2012.

[21] L. Fengzhi, L. Yi, L. Yingxi, and L. Zhongxuan, "Numerical simulation of coupled heat and mass transfer in hygroscopic porous materials considering the influence of atmospheric pressure," Numerical Heat Transfer, Part B: Fundamentals, vol. 45, no. 3, pp. 249-262, 2004.

[22] Y. Li and Q. Zhu, "A model of coupled liquid moisture and heat transfer in porous textiles with consideration of gravity," Numerical Heat Transfer; Part A: Applications, vol. 43, no. 5, pp. 501-523, 2003.

[23] Y. Cheng, J. Niu, and N. Gao, "Thermal comfort models: a review and numerical investigation," Building and Environment, vol. 47, no. 1, pp. 13-22, 2012.

[24] M. Fu, W. Weng, W. Chen, and N. Luo, "Review on modeling heat transfer and thermoregulatory responses in human body," Journal of Thermal Biology, vol. 62, pp. 189-200, 2016.

[25] B. Givoni and R. F. Goldman, "Predicting rectal temperature response to work, environment, and clothing," Journal of Applied Physiology, vol. 32, no. 6, pp. 812-822, 1972.

[26] A. P. Gagge, A. Fobelets, and L. Berglund, "A standard predictive index of human response to the thermal environment," ASHRAE Transactions, vol. 92, pp. 709-731, 1986.

[27] G. Fu, A transient 3-D mathematical thermal model for the clothed human [Ph.D. thesis], Kansas State Unviersity, 1995.

[28] J. A. Stolwijk, A Mathematical Model of Physiological Temperature Regulation in Man, National Aeronautics and Space Administration, 1971.

[29] D. Fiala, G. Havenith, P. Bröde, B. Kampmann, and G. Jendritzky, "UTCI-Fiala multi-node model of human heat transfer and temperature regulation," International Journal of Biometeorology, vol. 56, no. 3, pp. 429-441, 2012.

[30] Y. Tang, Y. He, H. Shao, and C. Ji, "Assessment of comfortable clothing thermal resistance using a multi-scale human thermoregulatory model," International Journal of Heat and Mass Transfer, vol. 98, pp. 568-583, 2016. 
[31] W. G. Weng, X. F. Han, and M. Fu, "An extended multisegmented human bioheat model for high temperature environments," International Journal of Heat and Mass Transfer, vol. 75, pp. 504-513, 2014.

[32] L. Yi, M. Aihua, W. Ruomei et al., "P-smart-a virtual system for clothing thermal functional design," Computer-Aided Design, vol. 38, no. 7, pp. 726-739, 2006.

[33] Y. Li, “The science of clothing comfort”, Textile Progress, vol. 31, no. 1-2, pp. 1-135, 2001.

[34] A. S. W. Wong, Y. Li, P. K. W. Yeung, and P. W. H. Lee, "Neural network predictions of human psychological perceptions of clothing sensory comfort," Textile Research Journal, vol. 73, no. 1, pp. 31-37, 2003.

[35] A. S. W. Wong, Y. Li, and P. K. W. Yeung, "Predicting clothing sensory comfort with artificial intelligence hybrid models," Textile Research Journal, vol. 74, no. 1, pp. 13-19, 2004.

[36] Z. Wang, Y. Li, Y. L. Kowk, and C. Y. Yeung, "Mathematical simulation of the perception of fabric thermal and moisture sensations," Textile Research Journal, vol. 72, no. 4, pp. 327-334, 2002.

[37] X. Luo, W. Hou, Y. Li, and Z. Wang, "A fuzzy neural network model for predicting clothing thermal comfort," Computers and Mathematics with Applications, vol. 53, no. 12, pp. 1840-1846, 2007.

[38] M. J. Buller, W. J. Tharion, S. N. Cheuvront et al., "Estimation of human core temperature from sequential heart rate observations," Physiological Measurement, vol. 34, no. 7, article 781, 2013.

[39] A. Mao, Y. Li, X. Luo, R. Wang, and S. Wang, "A CAD system for multi-style thermal functional design of clothing," $C A D$ Computer Aided Design, vol. 40, no. 9, pp. 916-930, 2008.

[40] A. Mao, J. Luo, Y. Li, R. Wang, G. Li, and Y. Guo, "Engineering design of thermal quality clothing on a simulation-based and lifestyle-oriented CAD system," Engineering with Computers, vol. 27, no. 4, pp. 405-421, 2011.

[41] W. L. Kenney, J. Wilmore, and D. Costill, Physiology of Sport and Exercise, Human Kinetics, 6th edition, 2015. 

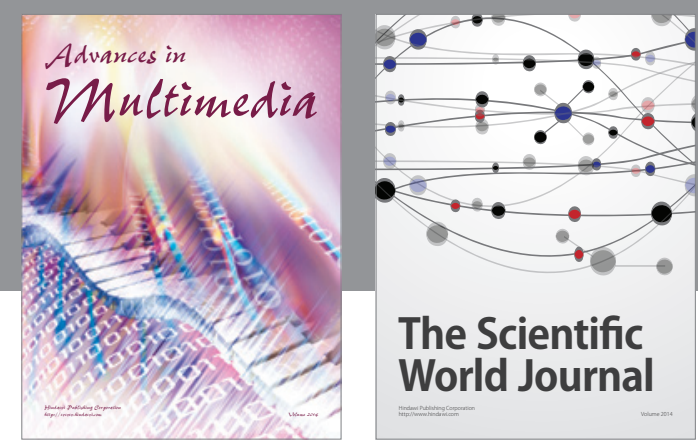

The Scientific World Journal
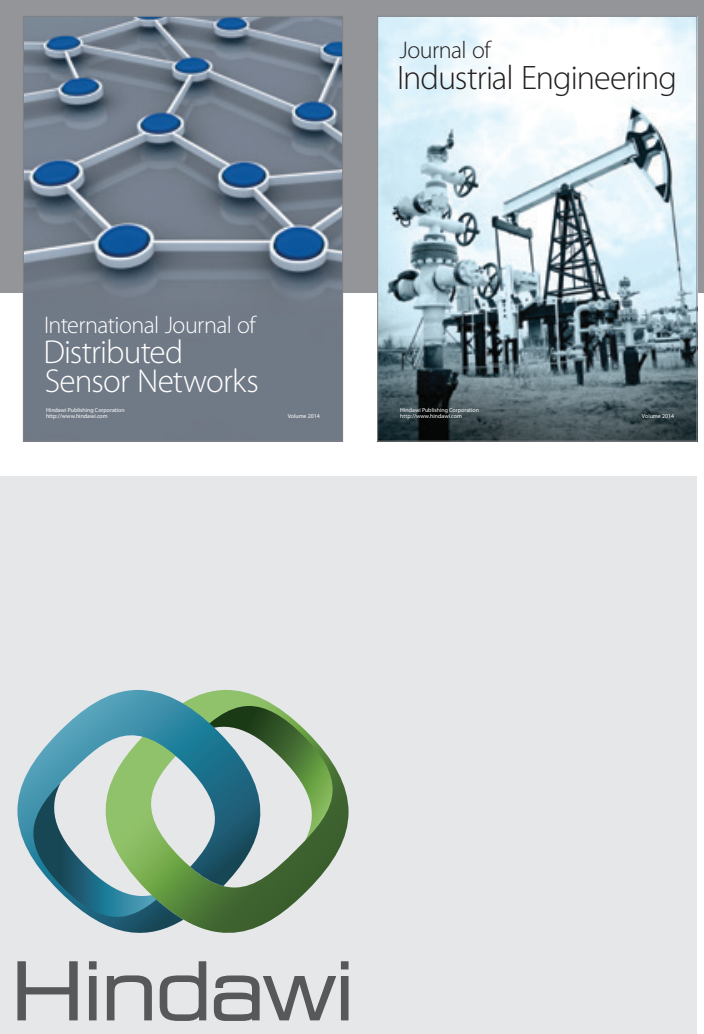

Submit your manuscripts at

http://www.hindawi.com

\section{Computer Networks} and Communications
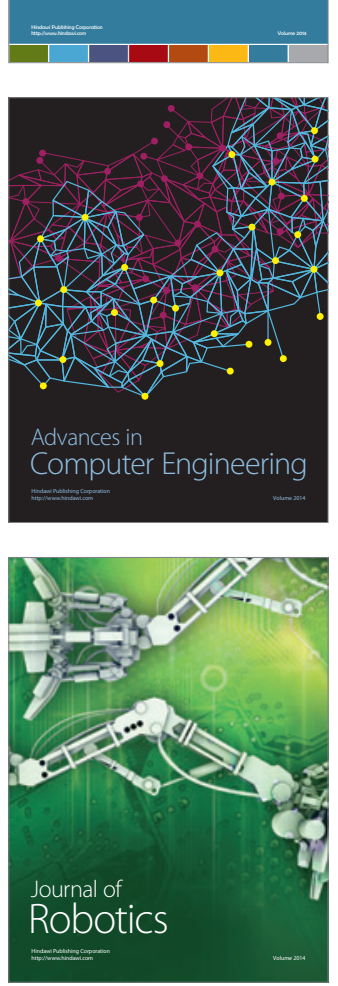
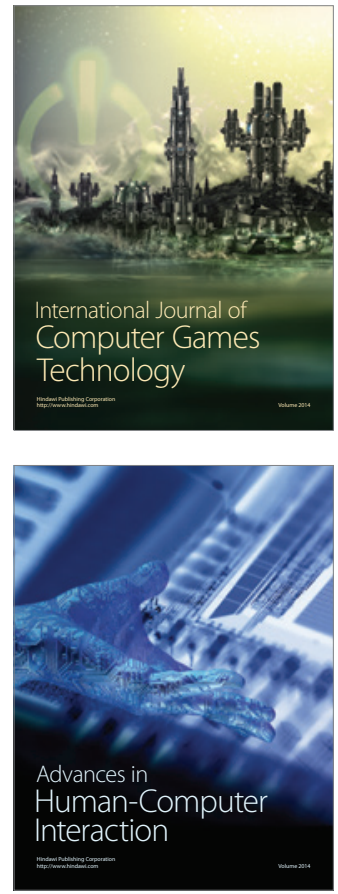
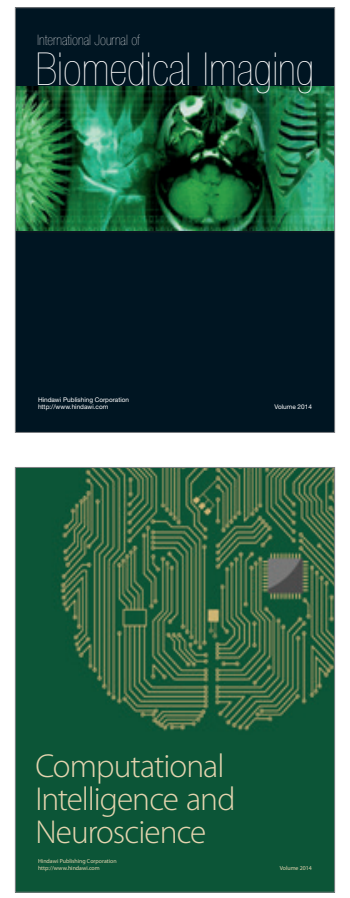
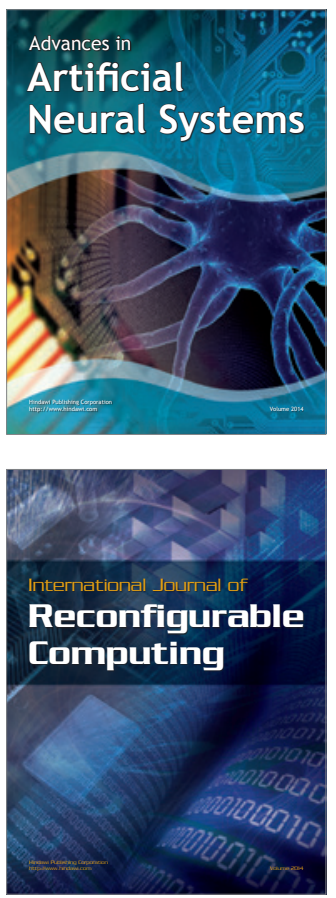
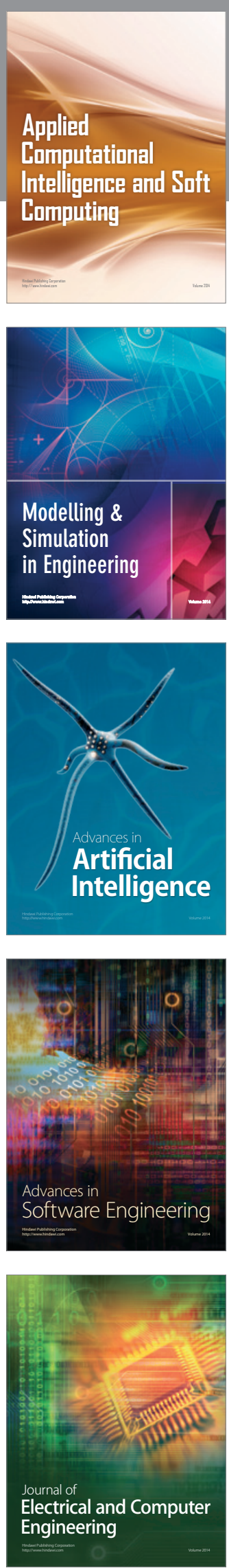